\author{
بررسى تأثير تالاب آلاكل بر تصفيه آب رودخانه اترى \\ رامين رخشانى، معصومه فراستى"، على حشمت يور و سيدمرتضى سيديان'

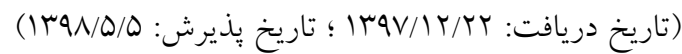

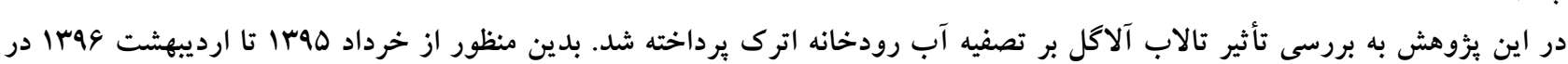

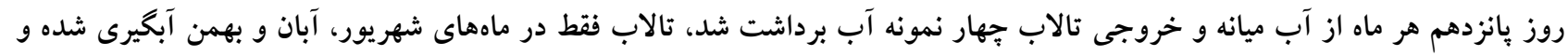

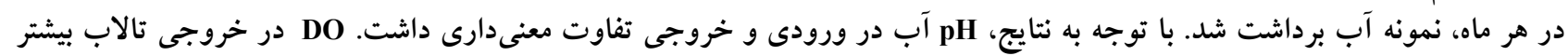

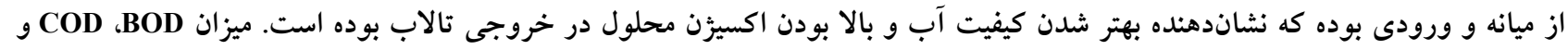

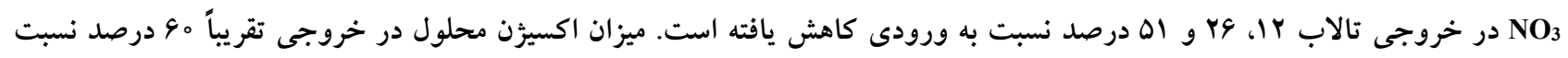

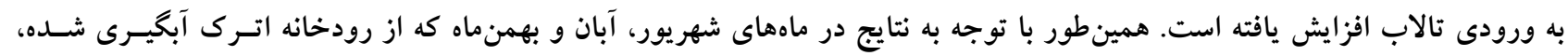

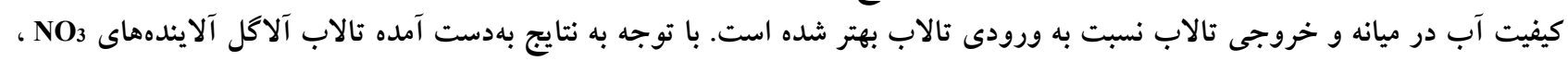

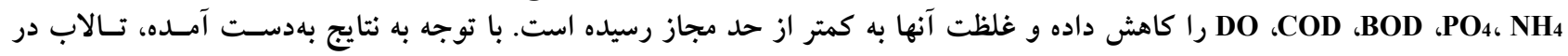

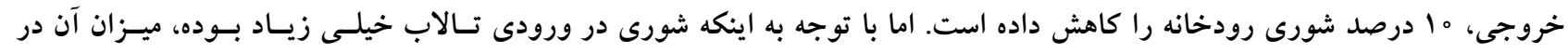

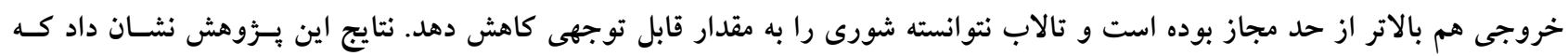

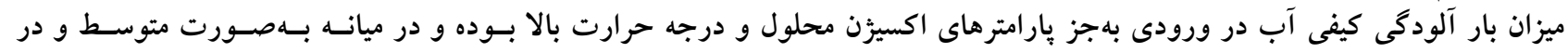

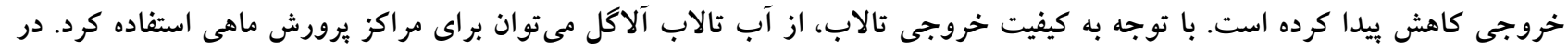

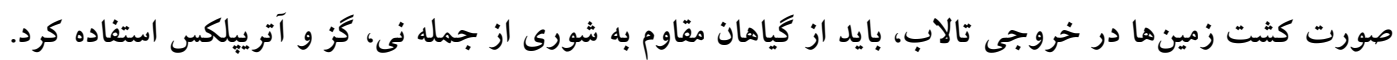

وازههاى كليدى: كيفيت آب، تصفيه طبيعى، تالاب آلاگل، نيترات 
نفر و همكاران به بررسى غلظت برخى فلزهاى سـنخين در آب آب آلمان

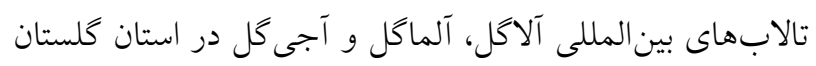

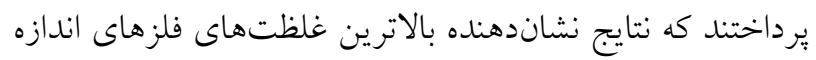

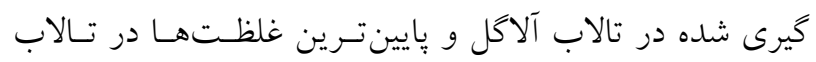

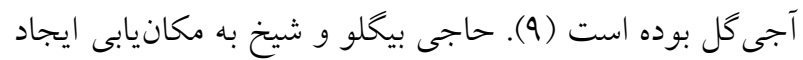

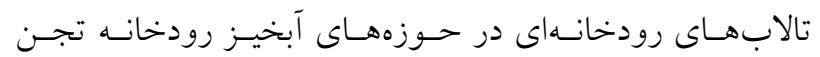
يرداختند (r). تانوير و همكاران در يُزوهشى، عملكـرد تـالاب

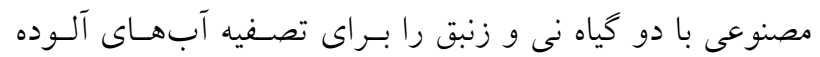

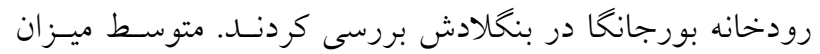

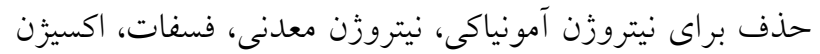

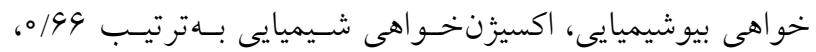

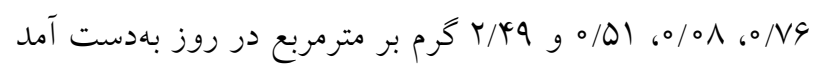

در يُزوهشى با عنوان مقايسه عملكرد بركههاى تثبيت و تالاب

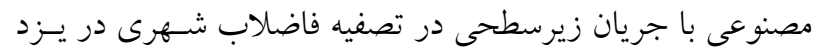
به اين نتيجه رسيدند كه راندمان حسـف BOD، COD و فسـفات در فصل باييز و تابستان بيشتر از ساير فصل ها بوده است؛ بنابر اين رسين

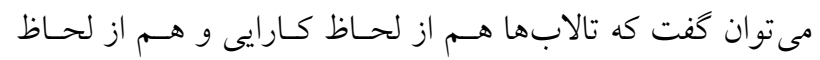

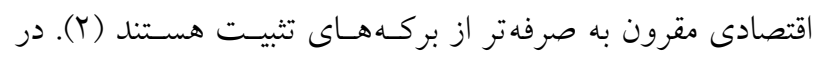

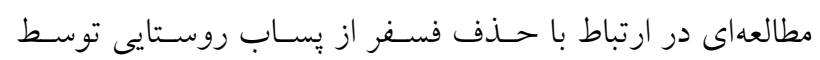

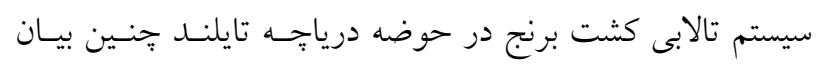

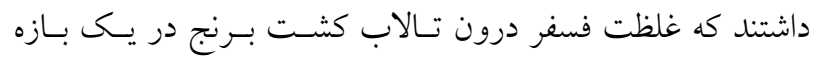

زمانى بهطور قابل توجهى كاهش ييدا كرده است (4).

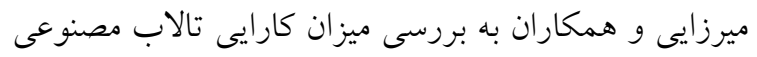

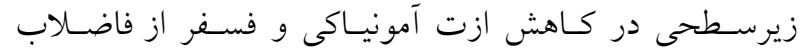

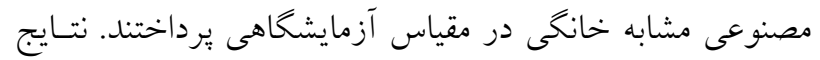

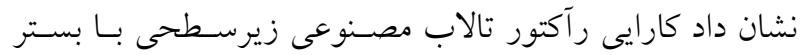

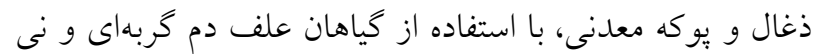

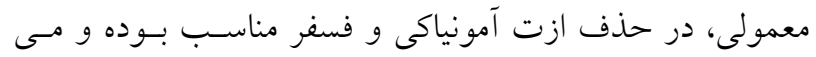
تواند با فراهم كردن شر ايط مناسب راهبرى و نخهدارى بهعنوان يك جايخزين دوستدار محيط زيست بهجاى ساير سيستمهـاى مكانيكى تصفيه فاضلاب باشد (N).

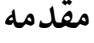
افزايش آلايندهها از جمله نيتروزن و فسفر در منابع آبسى باعـث

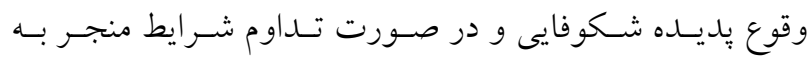
جلبكى شدن و كاهش كيفيت آب بر اثر اوتريفيكاسيون مىشودود.

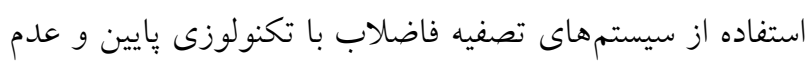

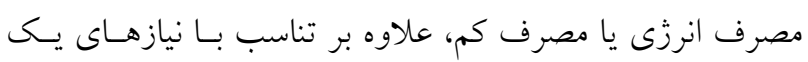

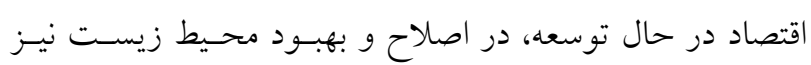

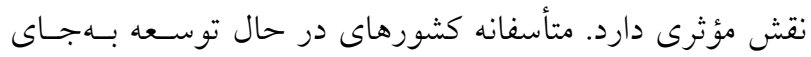

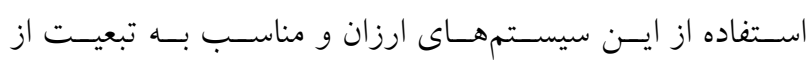

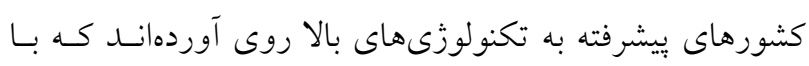
مشكلات متعدد بهرهبردارى، نخهارى، مصرف انرزى زياد و....

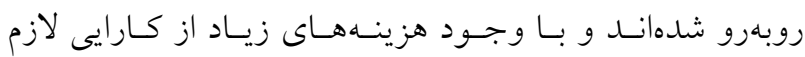
برخوردار نيستند و اين در صورتى است كه اكنون سيستمهـاى طبيعى بهعلت عدم نياز به انرزى و كـارايى بـالا مـورد توجـهـ و علاقه جدى كشورهاى بيشرفته قرار كرفتهاند (IV). كشـورهاى

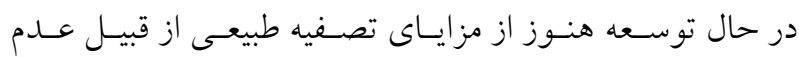

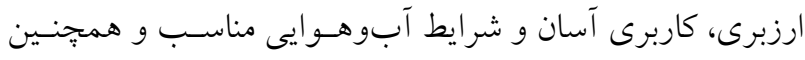

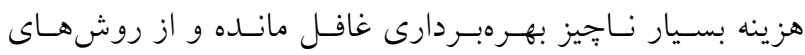
متداول و ييشرفته تصفيه فاضلاب و صـرف هزينـههـاى بسـيار

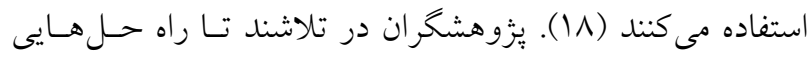

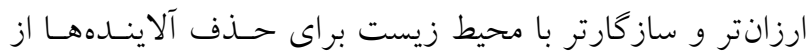

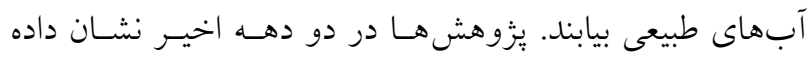

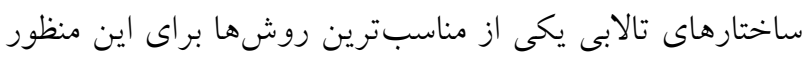

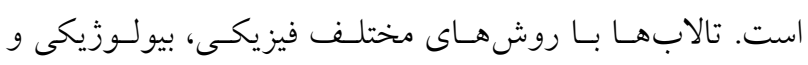

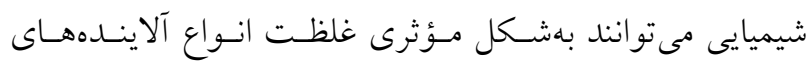

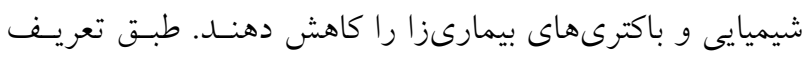

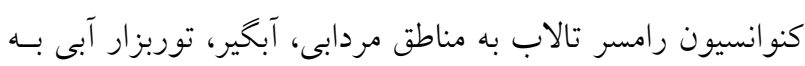

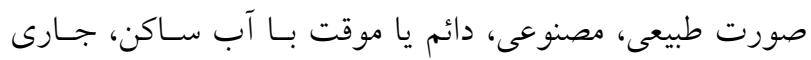

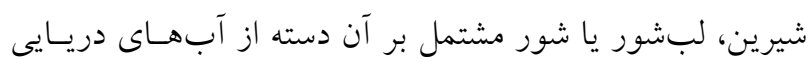

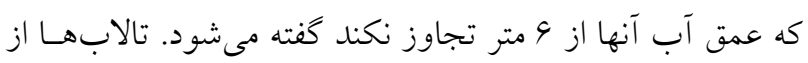

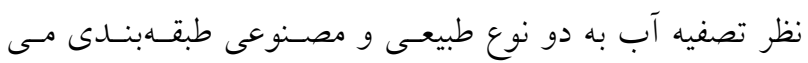
شوند. قدمت تالابهاى طبيعى به قدمت زمين مسىرســ (1) (1). 


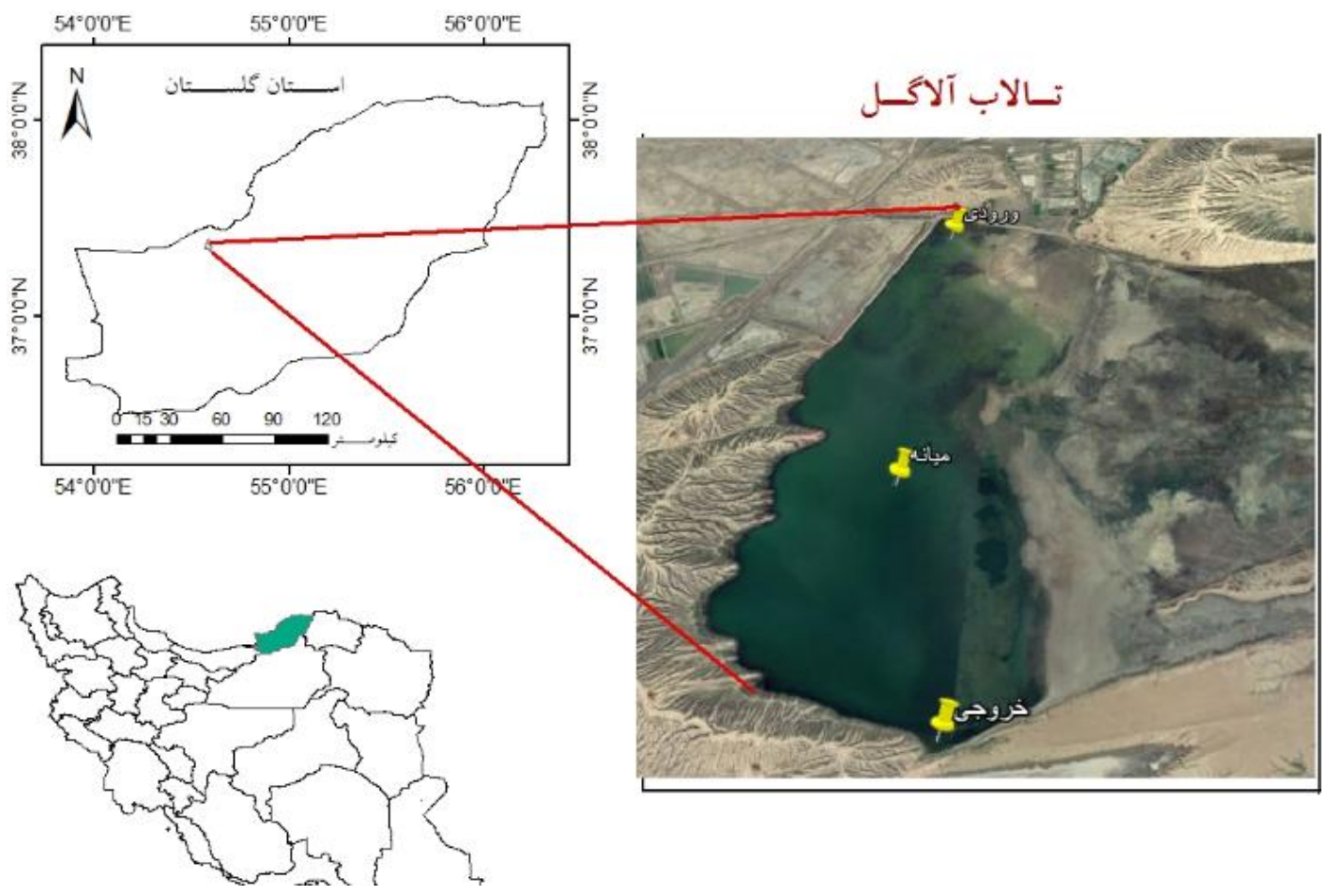

شكل ا. نقشه منطقه مورد مطالعه

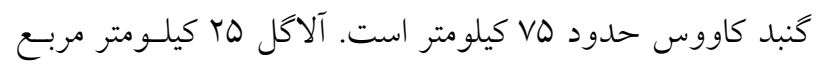

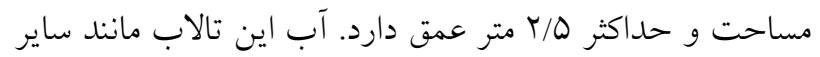

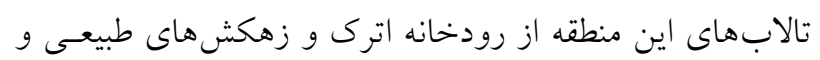

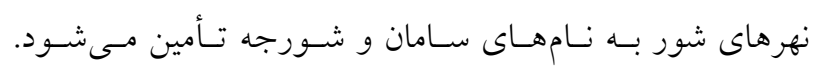

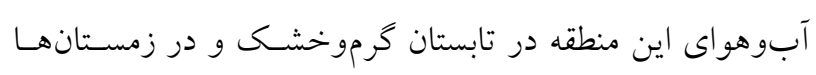

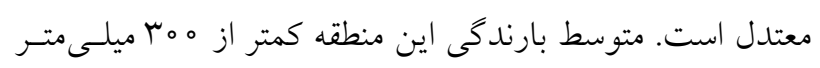

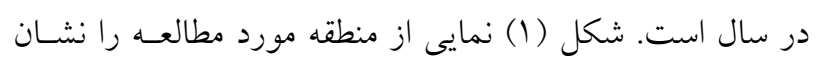
مى دهد. در اين يُزوهش، سه ايستخاه در ورودى رودخانـه اتـرى بـهـ

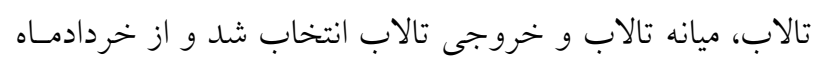

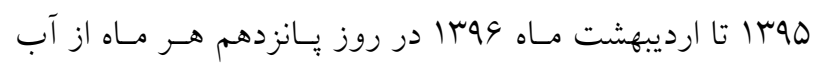

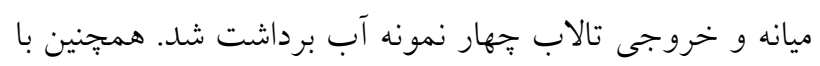

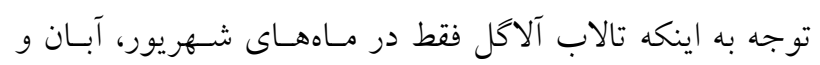

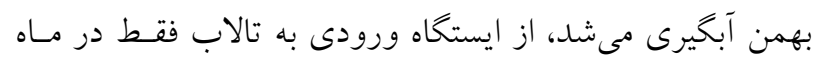

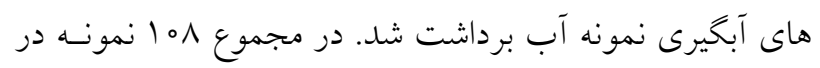

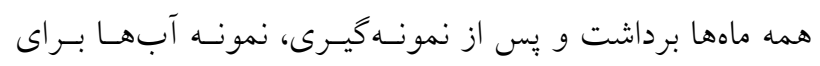

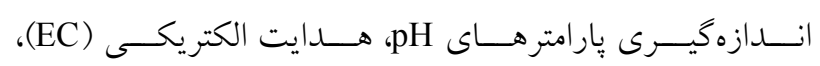
in

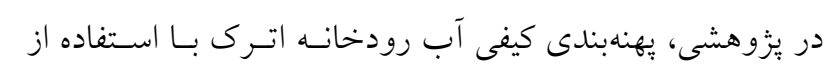

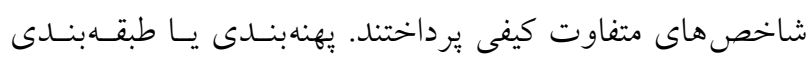

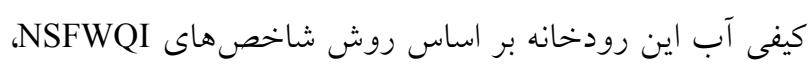
BCWQI

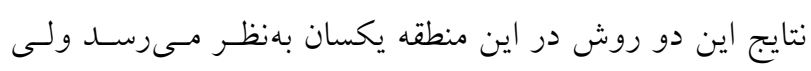

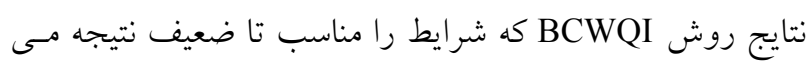

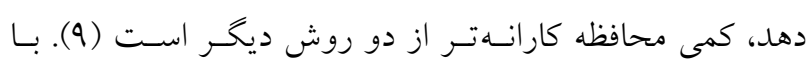

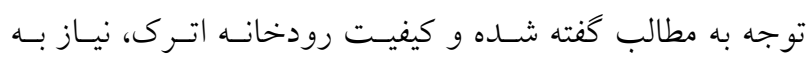

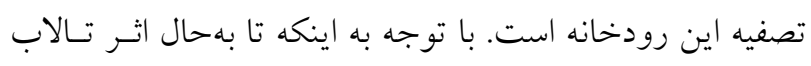

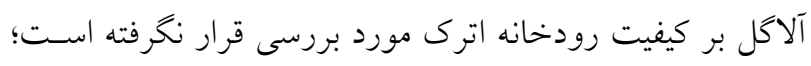

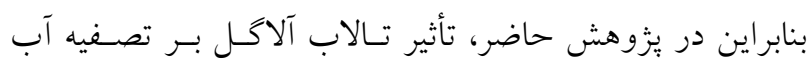
رودخانه اترى مورد بررسى قرار كرفت.

مواد و روشها تالاب آلاكَ بزرگترين درياجه استان كلستان و يك تالاب آب

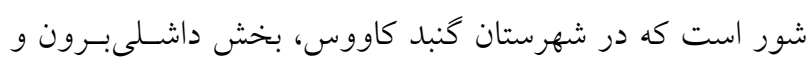

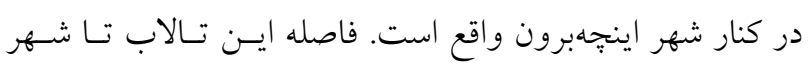


جدول ا. يارامترهاى هواشناسى تالاب آلاگل در ماههاى مورد مطالعه

\begin{tabular}{|c|c|c|c|c|c|c|c|c|c|c|c|c|}
\hline ارديبهشت & فروردين & | ل | ل اسفند & بهمن & دى & 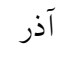 & 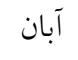 & مهر & شهريور & مرداد & تير & خرداد & ماه \\
\hline$\Delta / \Delta$ & $r / \varphi$ & $T / V$ & $1 / 1$ & $1 / 4$ & $1 / 4$ & r & $r / 9$ & $\Lambda / \Delta$ & $\Lambda / \Delta$ & $9 / 1$ & $\wedge$ & تبخير (ميلى متر در روز) \\
\hline$r Y / \mu$ & $I V / T$ & $1 T / 0$ & $9 / 0$ & $V / r$ & $\mathrm{~V} / \mathrm{V}$ & $10 / 1$ & $I V / V$ & rq & 洒 & $\Gamma / / 0$ & $\mu \circ / \Lambda$ & دما (ميلى متر) \\
\hline $0 / r$ & Tr & $r Y / r$ & $\mu \circ / v$ & $r V / I$ & $r V / I$ & pr/s & 9 & $9 / 9$ & 11 & $ه / 1$ & 。 & بارش (ميلى متر) \\
\hline
\end{tabular}

جدول r. دبى ورودى به تالاب آلاگل در ماههاى مختلف

\begin{tabular}{|c|c|c|c|c|c|c|c|c|c|c|c|c|}
\hline ارديبهشت & فروردين & اسفند & بهمن & دى & آذر & آبان & مهر & شهريور & مرداد & تير & خرداد & ماه \\
\hline$\circ$ & $\circ$ & 。 & $Y / \Delta \Lambda$ & 。 & 。 & $Y / V Q$ & 。 & $\uparrow / \Gamma \Delta$ & $\circ$ & $\circ$ & 。 & (متر مكعب بر \\
\hline
\end{tabular}

استفاده و رسم نمودار روند تغييرات زمانى و مكـانى مقـادير در

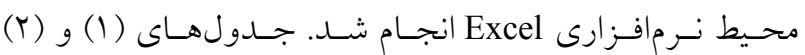
يار امترهاى هواشناسى منطقه تالاب آلاكل را در مـاههـاى مـورد

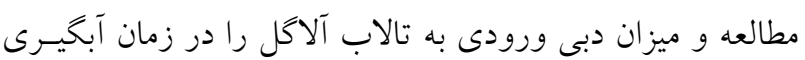
(شهريور، آبان و بهمنماه) نشان مى نىهد.

\section{نتايج و بحث}

تجزيه واريانس كرت هاى خرد شــده بــراى فاكتورهـاى كيفيـت آب در طول دوره نمونهبردارى در جدول (r) آورده شده است.

مقايسه ميانگين فاكتورهاى كيفيت آب در طول دوره نمونهبردارى فاكتورهايى كه اثر متقابل آنها معنى دار شد از روش بـرشدهـى

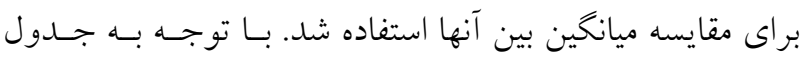
(ז)، اثرات متقابل زمان و مكان خروجسى فاكتورهـاى فسـفات،

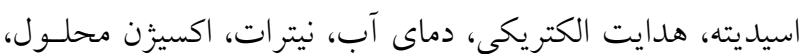
اكسيزن مورد نياز شـيميايى و اكسـيزن مـورد نيـاز بيوشـيميايى معنى دار شد. نتايج مقايسه ميانخين حاصل در جدول (Y) و (ه)

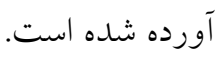
جدول مقايسـه ميـانگين دادههـا (جــدول †) نشـان داد كـهـ

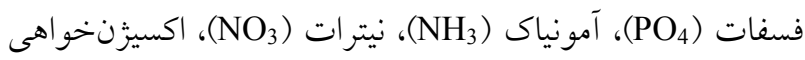
بيوشيميايى (BOD)، اكسيزنخواهى شيميايى (COD) و اكسيزن محلول (DO) بهسرعت به آزمايشخاه منتقـل شــــ بــراى انــازه كيـرى دمـاى آب از دماسـنج اسـتاندارد (مــل Waterproof Ectestr 11 هدايت الكتريكى با استفاده از دستخاه هدايتسنج الكتريكى، اسيديته آب با دستخاه pH متر، اندازه خيـرى فسـفات، نيترات و آمونياك با استفاده از دستخاه اسيكتروفتومتر، BOD بـا

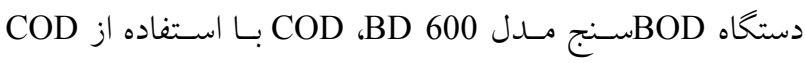

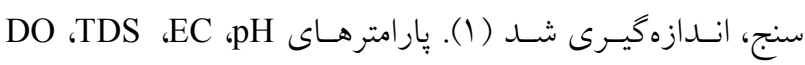
جريان ورودى و خروجى با اسـتفاده از دسـتخاه بورتابـل مــل ندازه كيرى شد. بهمنظور مقايسه خصو صيات HQ Y d HACh كيفى آب در مكان و زمانهاى مختلف از آزمون كرتهاى خرد شده در واحد زمان استفاده شد. بدين منظور ابتـدا نرمـال بـودن

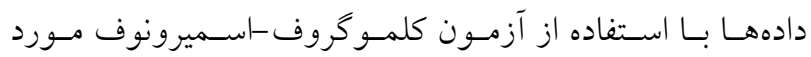
بررسى قرار گرفت. در صورت نرمـال نبـودن سـرى داده از بـا تبديل مناسب BOX-COX لخـاريتمى، دادههــا نرمـاليزه شـدند. درنهايت با انتقال دادهها به نرمافزار SAS، آزمون كرتهاى خرد شده در واحد زمان (Split plot in time) انجام شد. براى انجـام

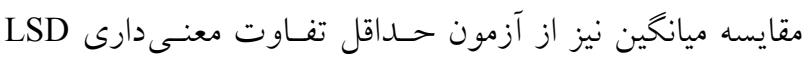


جدول r. تجزيه وارايانس فاكتورهاى كيفيت آب در طول دوره نمونهبردارى

\begin{tabular}{|c|c|c|c|c|c|c|c|c|c|c|}
\hline اكسيزنخواهى & نيترات & اسيديته & دما & نياز شيميزيى مورد & آمونياك & فسفات & اكسيزن & هدايت الكتريكى & آزادى درجه & منابع تغيير \\
\hline$\circ / \circ \Delta^{* *}$ & $\circ / \circ \circ r^{* *}$ & $9 / 94^{* *}$ & $\circ / \circ \circ \Upsilon^{* *}$ & $\% / \circ r^{* *}$ & $\circ / \circ \circ Q^{* *}$ & $0 / 001^{* *}$ & $\circ / \circ \circ 9^{* *}$ & $\circ^{* *}$ & r & تكرار \\
\hline$r N / 9 r^{* * *}$ & $0 / 04^{* *}$ & $1 / 001^{* *}$ & $0 / T V^{* *}$ & $r q / \Delta \Delta^{* *}$ & $0 / 99^{* *}$ & $1 / \circ 0^{* *}$ & $V \circ / V q^{* *}$ & ०/००Я $\mu^{* *}$ & 1 & مكان \\
\hline س & $\circ / \circ \circ \circ V$ & $1 / 4 x$ & $0 / 001$ & OOOYY & $0 / 014$ & O००Y & $0 / 014$ & 。 & r & خطاى (1) \\
\hline$k \mid r / \circ k^{* *}$ & $4 / \circ \Delta^{* *}$ & $1 / 44^{* *}$ & $10 / 400^{* *}$ & $|\psi| \psi / 01^{* *}$ & $r / Y \psi^{* *}$ & $\circ / \Delta \wedge^{* *}$ & $199 / \circ r^{* *}$ & $\circ / \circ \circ \circ D^{* *}$ & 11 & زمان \\
\hline $1 / T Q^{* *}$ & $\% / \psi^{* *}$ & $r / 9 \varphi^{* *}$ &.$/ 01 \Lambda^{* *}$ & $q \mu .1^{* *}$ & $\circ / V_{0}^{* *}$ & $\circ / \circ V^{* *}$ & $T / T \varphi^{* *}$ & $\circ / 0001^{* *}$ & 11 & مكان × زمان \\
\hline \% YY & 0100004 & $Q / \circ V$ & $0 / 0009$ & .010 & $0 / 01 r$ & $\circ / 000 \wedge$ & \%० & 。 & 99 & خطاى (r) \\
\hline $0 / 91$ & $r / Y \Lambda$ & $1 / T \Lambda$ & $\circ N 1$ & .109 & $r / 9 V$ & $V / 4 Q$ & $\circ / \mu \Lambda$ & o/IVG & & ضريب تغييرات \\
\hline
\end{tabular}

جدول F. مقايسه ميانخين فاكتورهايى با اثرات متقابل معنىدار در مكان ميانه و زمانهاى مختلف دوره نمونهبردارى

\begin{tabular}{|c|c|c|c|c|c|}
\hline 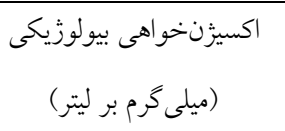 & (مليلى موس بر سانتىمتر) & 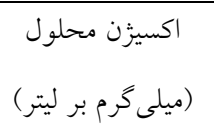 & اسيديته & (درجه سانتى گراد آب ) & ماههاى نمونه \\
\hline $\mid \psi / \circ \wedge \pm \circ / \circ Y^{d}$ & $r / r \Delta \pm \circ / \circ Y^{d}$ & $1 / N 9 \pm 0 / \circ Y^{b}$ & $\Lambda / Y^{\prime} \Delta \pm \circ / \circ Y^{d}$ & $\Upsilon \wedge / \Delta \pm \circ / \zeta^{c} \mathrm{c}$ & خرداد \\
\hline $19 / 09 \pm 0 / 00^{b}$ & $\Gamma / \mu_{ \pm \circ / \circ} r^{c}$ & $. / 91 \pm 0 / 01^{h}$ & $q /{ }^{\leftarrow} V \pm \circ / \circ r^{a}$ & $r 1 / 90 \pm 0 / /^{b}$ & تير \\
\hline $\mid V / V Q \pm \circ / \circ r^{a}$ & $r / q \pm \circ / \circ r^{b}$ & $\circ / \Delta \pm \circ / \circ r^{j}$ & $\Lambda / T \Delta \pm \circ / \circ \Delta^{f}$ & $\Gamma / q V \pm 0 / / r^{a}$ & مرداد \\
\hline $10 / \wedge 9 \pm \circ / \circ V^{c}$ & $r / V \pm \circ / \circ l^{a}$ & $\left.\circ / Y_{ \pm} \pm 0 / 0\right)^{k}$ & $N / 0 \mid \pm 0 / 01^{h}$ & $r V / \circ r \Delta \pm \circ / \circ \Delta^{d}$ & شهريور \\
\hline$|r / \Lambda| \pm 0 / 0 \psi \mathrm{\psi g}$ & $r / \Delta \wedge \pm \circ / /^{b}$ & $\circ / q \mu_{ \pm 0 / 0 Y^{i}}$ & $\Lambda / \mu \mid \pm 0^{\mathrm{e}}$ & $r T \pm 0 \mathrm{e}$ & مهر \\
\hline$|r / 0| \pm 0 / 04 f$ & $r / r \pm 0^{e}$ & $\circ / 91 \pm \circ / \circ \Upsilon^{h}$ & $\Lambda / Y \varphi \pm \circ / \circ Y^{f}$ & $|r \pm 0 /| \varphi^{h}$ & 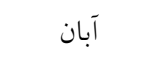 \\
\hline$|r /| 9 \pm 0 / 0 r^{h}$ & $r / l Y \pm o^{f}$ & $1 / M r^{\prime} \circ / \circ Y^{f}$ & $\Lambda / K Y \pm \circ / \circ Y^{d}$ & $9 / \circ \vee \Delta \pm \circ / 1 Q^{k}$ & آذر \\
\hline $11 / \wedge 9 \pm 0 / / r^{\mathrm{i}}$ & $r / / \pm \circ g$ & $I / Y Y \pm \circ / \circ V^{e}$ & $N / q^{r} \pm 0 / 01^{c}$ & $q / \uparrow \vee \Delta \pm \circ / \circ \Delta^{j}$ & دى \\
\hline$|1 / r| \pm 0 / 0 \mu^{\mathrm{k}}$ & $r_{ \pm \circ / 01^{h}}^{h}$ & $1 / 99 \pm 0 / 01^{a}$ & $\Lambda / \mathcal{A} \pm{ }^{\circ} \mathrm{c}$ & $V / / \pm 0^{1}$ & بهمن \\
\hline 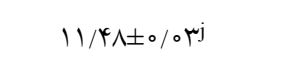 & $\Gamma / \Lambda \pm \circ / \circ \Delta^{g}$ & $1 / 9 \mathrm{~V} \pm \circ / \mathrm{T}^{\mathrm{c}}$ & $\Lambda / A Y \pm \circ / \circ Y^{b}$ & $11 / \Gamma \mathrm{V} \pm \circ / \circ \Delta^{\mathrm{i}}$ & اسفند \\
\hline $\mid r / V q \pm \circ / \circ \Delta^{g}$ & $r / \backslash \Delta \pm \circ /\left.0\right|^{f}$ & $\mid / \Lambda \pm \circ / \circ{ }^{c d}$ & $N /|Y \pm 0 / 0|^{g}$ & $\mid V / A Y \pm \circ / \circ \Delta^{g}$ & فروردين \\
\hline $\mid r / \backslash \Lambda \pm 0 / 0 \psi^{e}$ & $r / Y \pm 0 / 0 \psi^{e}$ & $1 / \circ \Upsilon^{ \pm} / \%{ }^{\mathrm{gg}}$ & $\Lambda / Y \Lambda \pm 0 / 0 \psi^{f}$ & $r_{0} / \circ V \pm \circ / /^{f}$ & ارديبهشت \\
\hline
\end{tabular}


جدول ه. مقايسه ميانخين فاكتورهايى با اثرات متقابل معنىدار در مكان ميانه و زمانهاى مختلف دوره نمونهبردارى

\begin{tabular}{|c|c|c|c|c|}
\hline اكسيز نخو اهى شيميايى & فسفات & آمونياك & 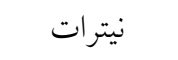 & ماههاى نمونهبردارى \\
\hline$r \Lambda / D I \pm \circ / \circ Y^{d}$ & $\circ / N_{ \pm \circ / \circ \wedge^{j}}$ & $r / A Y \pm 0 / 0 Y^{i}$ & $r / 11 \pm 0 /\left.0\right|^{e}$ & خرداد \\
\hline$r q / a r \pm \circ / \circ \Delta^{b}$ & $\circ / \wedge \mathcal{G}_{ \pm \circ / \circ \mathcal{G}^{\mathrm{e}}}$ & $r / \Delta r \pm \circ f$ & $r / l V \pm \circ / \circ r^{d}$ & تير \\
\hline 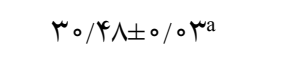 & $\left|/ Y Y_{ \pm 0 / 0}\right|^{a}$ & $\psi / / V_{ \pm \circ} / / \mathrm{kc}^{\mathrm{c}}$ & $r / 19 \pm 0 / 0 r^{d}$ & مرداد \\
\hline$r q / \circ \wedge \pm \circ / \circ V^{c}$ & $1 / 1 \pm 0^{b}$ & $\Delta / r \Delta \pm \circ / \circ /^{\mathrm{a}}$ & $r / \Delta \pm \circ / \circ \varphi^{a}$ & شهريور \\
\hline$r V / / \Lambda \pm \circ / \circ \mathrm{Cf}^{\mathrm{f}}$ & $1 / \circ Y_{ \pm} / \circ 1^{c}$ & $Q / \circ Y_{ \pm} \pm / \circ Y^{b}$ & $r / \mu_{4} \pm 0 /\left.0\right|^{c}$ & مهر \\
\hline$T V / Q \pm \circ / 0 \varphi^{e}$ & $1 / 1 \pm 0 /\left.0\right|^{b}$ & $0 / \circ q_{ \pm \circ / \circ 1^{b}}$ & $r /|r \pm 0 / 0|^{b}$ & آبان \\
\hline$r Q / 90 \pm 0 / \circ r^{i}$ & $\circ / 9 r \pm \circ^{d}$ & $Y \pm 0 / r Y^{d}$ & $r / r V \pm \circ /\left.0\right|^{c}$ & آذزر \\
\hline$r \Psi / 9 \Lambda \pm 0 / / \mu^{1}$ & $\circ / V \Lambda \pm \circ / \circ r^{f}$ & $\Gamma / \wedge \varepsilon_{ \pm \circ} / \circ \Delta^{\mathrm{e}}$ & $r / \circ V \pm \circ / \circ r^{e}$ & دى \\
\hline$r \mu / Q \mu_{ \pm 0 / \circ \mu^{k}}$ & $0 / 49 \pm 0 / 0 \Upsilon^{i}$ & $r / 11 \pm 0 / 0)^{h}$ & $1 / \Lambda Y_{ \pm} \circ / \circ Y^{f}$ & بهمن \\
\hline$r \Psi / \Lambda \pm \circ / \circ \mu^{j}$ & $\circ / \Delta Y_{ \pm \circ} h$ & $r / 19 \pm \circ g$ & $1 / V Y \pm \circ / \circ Y_{g}^{g}$ & | اسفند \\
\hline$r Q / \Lambda Y \pm \circ / \circ Q^{h}$ & $\circ / 99 \pm 0 / 0 \% g$ & $\Gamma / \Delta \pm \circ / \circ Y^{f}$ & $1 / \Lambda \Delta \pm \circ / \circ r^{f}$ & فروردين \\
\hline 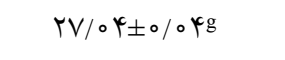 & $\circ / \Lambda \Lambda \pm \circ / \circ \gamma^{\mathrm{e}}$ & $\psi / 19 \pm 0 / 4<c$ & $1 / \uparrow \pm \circ / \circ \wedge^{c}$ & ارديبهشت \\
\hline
\end{tabular}

درجه) و بيشترين بارش (4/9 (Y))، اكسيزن محلول آب افـزايش داشته است. بارندگى با ايجـاد تلاطـم در آب باعـث افـزايش اكسيزن محلول شده است. در بهمنماه بهدليل بالا بودن ميـزان

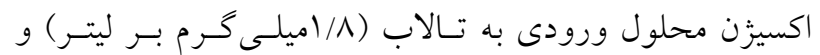
كاهش دمـاى آب ( V/I درجـهـ سـانتى گـــاد)، ميـزان اكسـيزّن محلول در ميانه تالاب بيشتر شده است. جلبك ها با كمك نور خورشيد و مواد مغذى، فتوسنتز كرده و اكسيزن محلول توليـد مىشود. كمترين مقدار اكسيزن محلول مربوط به شهريورماه و

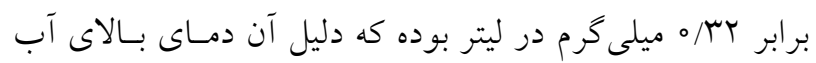

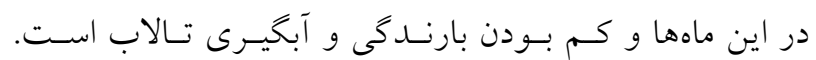

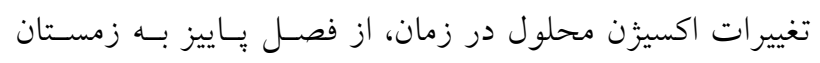
حالت افزايشى و سِّ روند كاهشى داشت. در ميانـه تـالاب

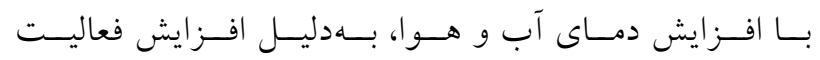
ميكرواركانيسمهاى هوازى در سطح آب، ميكرو اور گانيسـمهــا اكسيزن محلول را مصرف كرده و باعث كـاهش آن شـدهانـد. بنابراين در فصل هاى گرم و دماى بـالاى آب، ميـزان اكسـيزّن محلول كمتر شده است. همجنهـين در زمـان آبخيـرى بـهدليـل ورود آب رودخانسه بـا دبسى ه/ أ مترمكعسب در ثانيـه، ميـزان
بيشترين ميزان دماى آب در فصل تابستان بهويزه تير و مرداد بـه

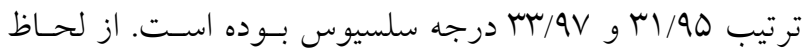
آمارى بين تمام فصل ها اختلاف معنى دار مشاهده شــــ اهميـت درجه حرارت بهدليل تأثير آن در انجـام واكـشـهـــ شـيميايى است كه در آب اتفــاق مسى افتــــ. افـزايش درجـهـ حــرارت آب، كاهش ميزان دبى آب را بهدنبال داشته و درنهايت باعث كـاهش

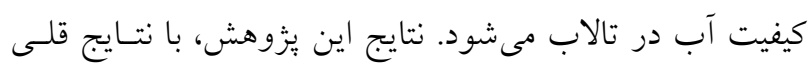
يور و علامتيان كه با افزايش درجسه حـــارت، سـرعت افـزايش BOD دما افزايش و كيفيت آب كاهش يافته است مطابقت داشت (Y). با توجه به جدول (Y)، اسيديته در محسدوده

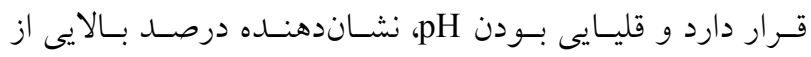
نمكهاى محلول در آب اسـت. بيشـترين اسـيديته مربسوط بـه

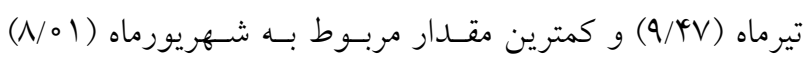
بـوده و تفــاوت اسـيديته در مـاههـاى مختلـف معنسى دار اسـت

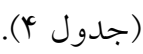
در آبانماه بـهدليـل بـالا بـودن ميـزان اكسـيزن محلـول آب

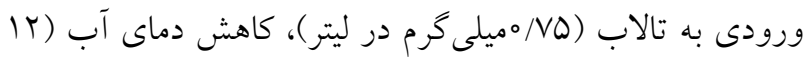


داشت (9) (1). تغييرات اكسيزن بيوشيميايى در ماههاى مختلف غير از مهر و فروردين معنى دار بود.

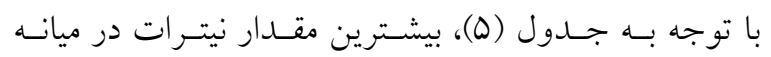

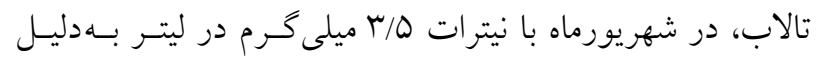

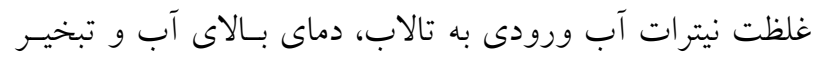

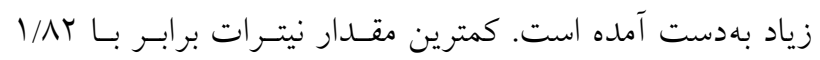

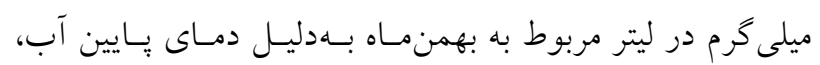

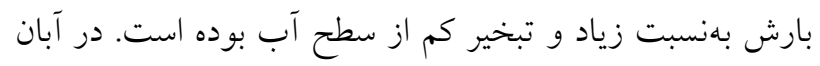

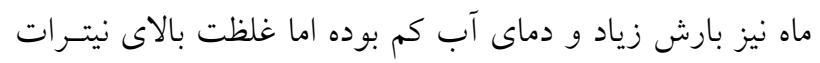

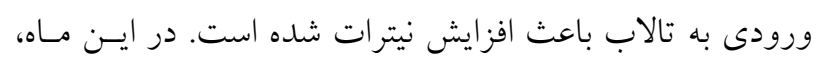

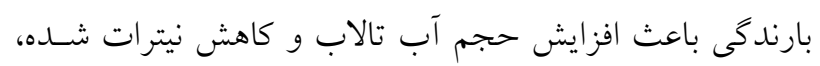

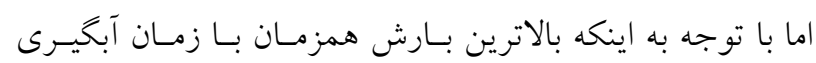

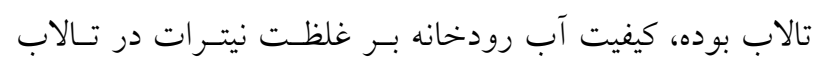
تأثير كذاشته و آن را افزايش داده است.

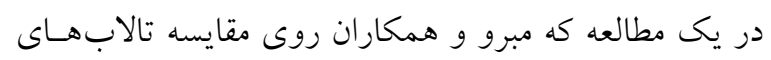

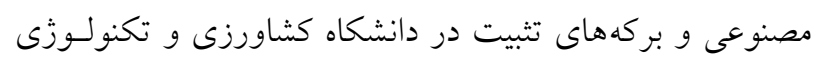

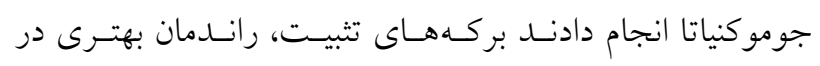

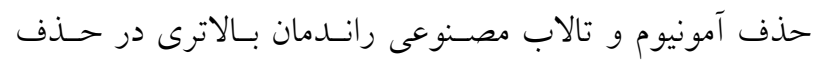

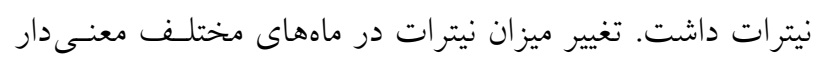

شد (4). (9)

با توجه به جدول (ه)، بيشترين مقدار آمونيـاك مربـوط بـهـ

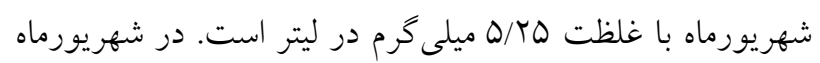

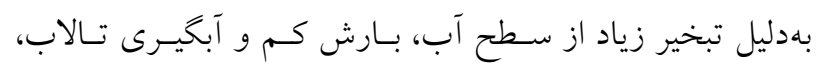

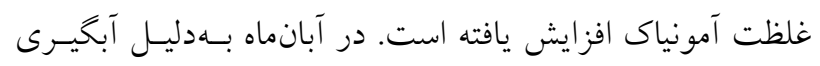

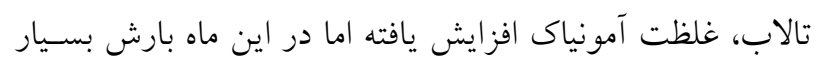

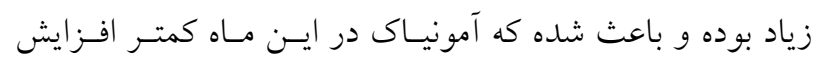

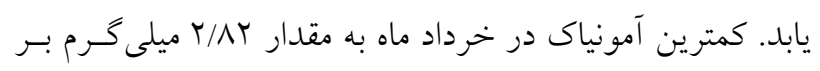
ليتر بهدست آمد. مبرو و همكاران در تحقيقى به نتيجه رسـيدند

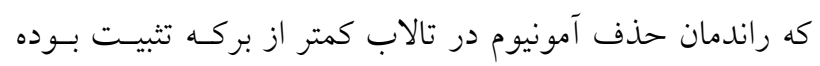

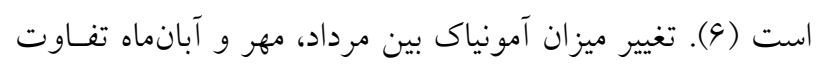

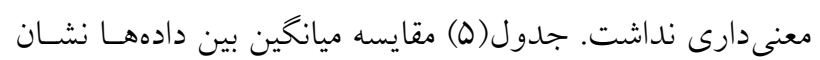

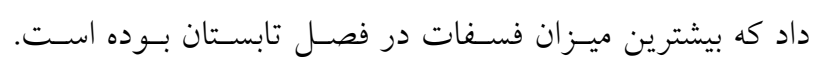

اكسيزن محلول آب رودخانه بر ميزان اكسيزن محلـول تـالاب

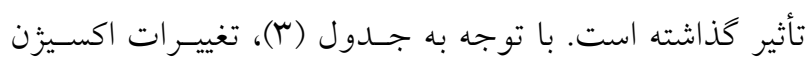
محلول در ماههاى مختلف معنى دار بود.

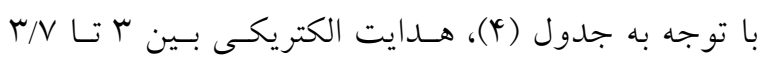

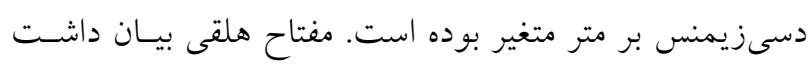

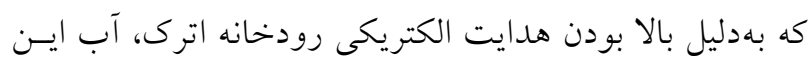

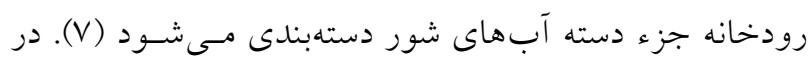

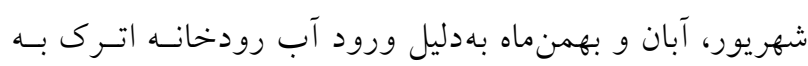

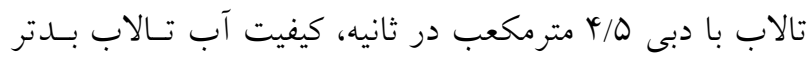

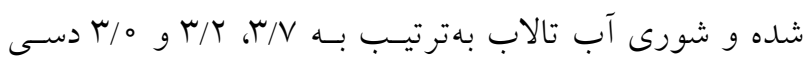

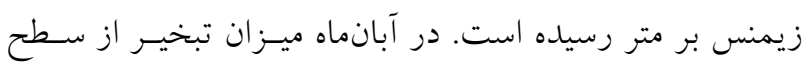

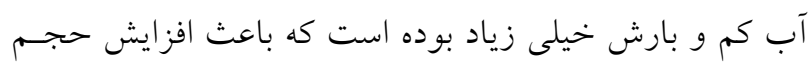

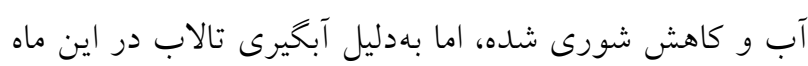

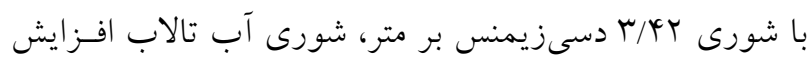

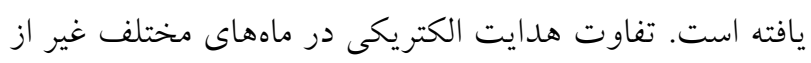

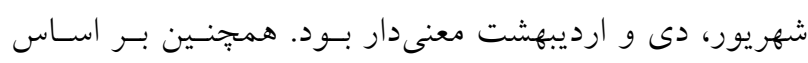

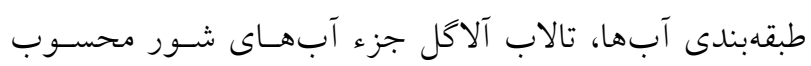
مىشود.

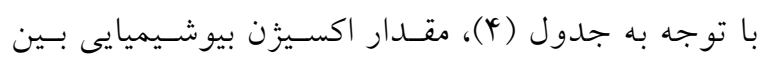

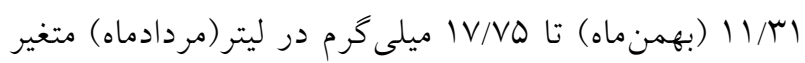

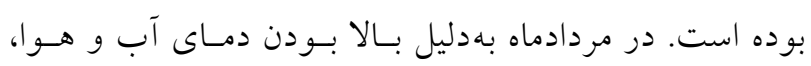

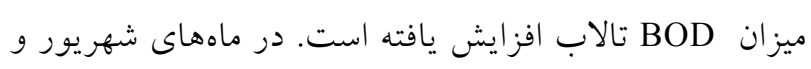

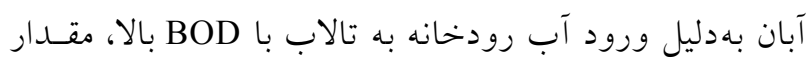

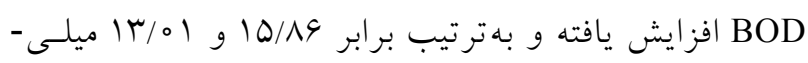

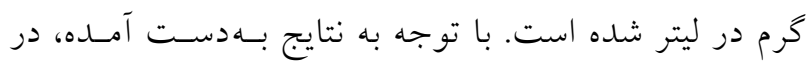

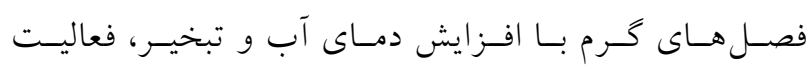

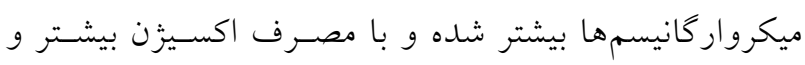

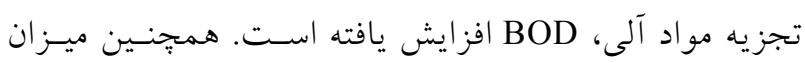

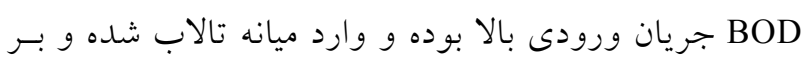

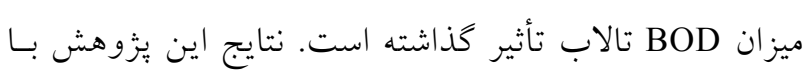

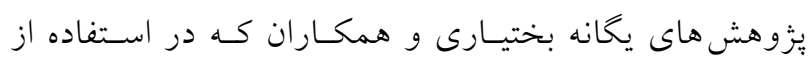

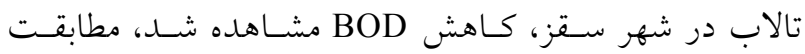


محلول در آب است (10). بـا توجسه بـه جــدول (9)، بيشـترين

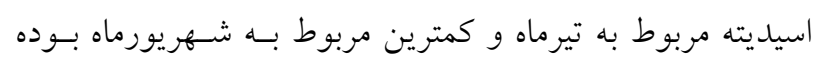

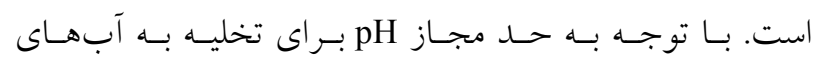

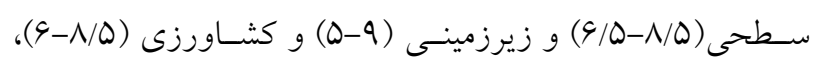

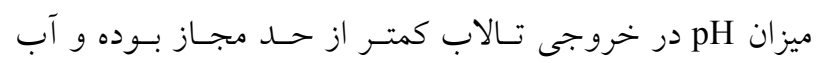
تابلاب مشكلى از نظر pH مندارد.

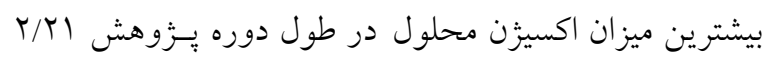

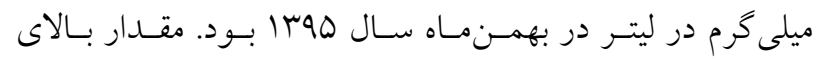

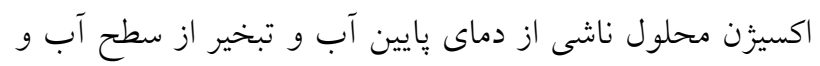

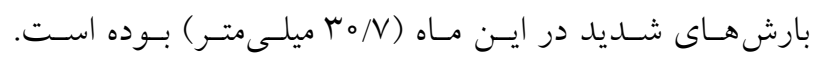

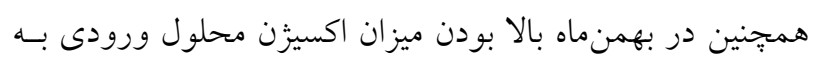

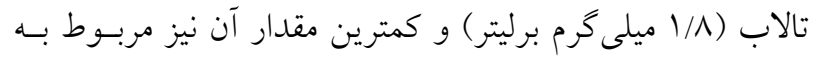

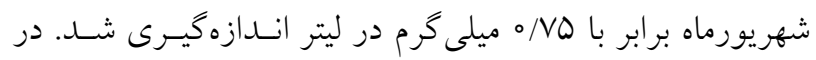

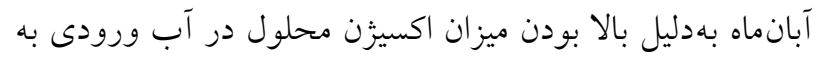

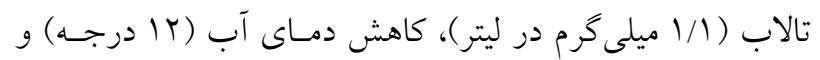

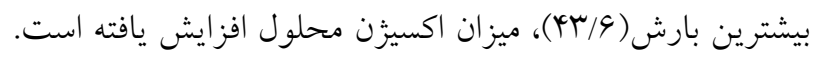

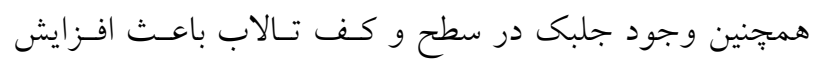

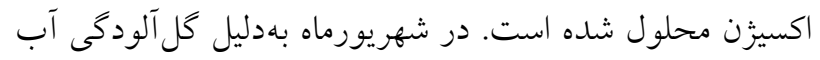

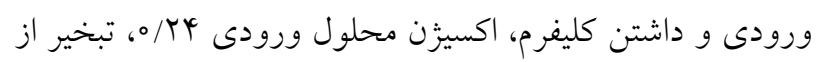

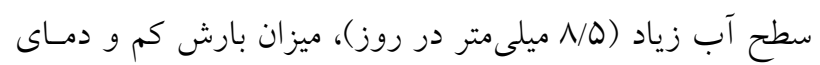

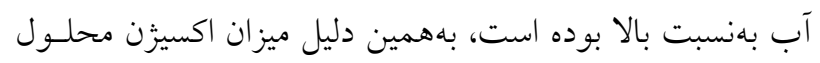

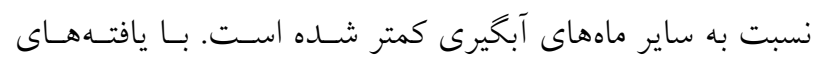

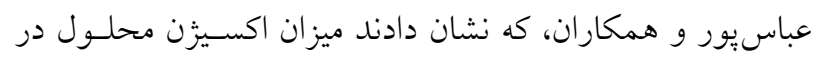

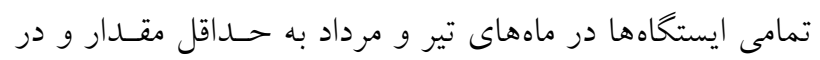
زمستان به حداكثر مقدار خود مىرسد تا حدودى مطابقـت دارد

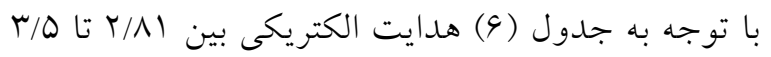

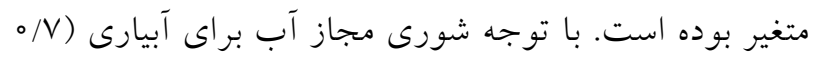

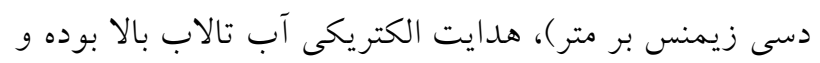

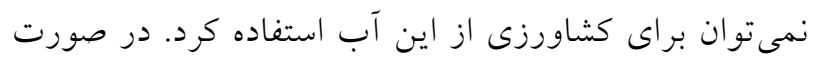

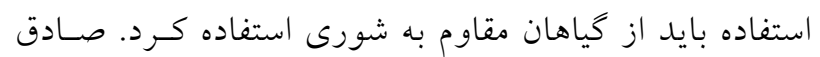

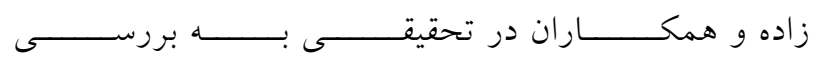

بيشترين مقدار فسفات در شهريور و آبانماه برابر // ميلى كرم

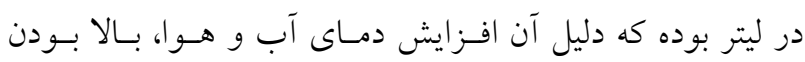
تبخير از سطح آب و آبخيرى در اين ماهها است. كمترين مقـدار

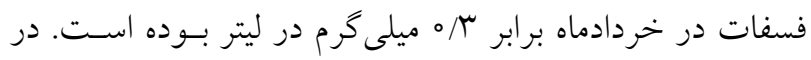

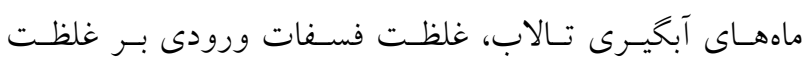

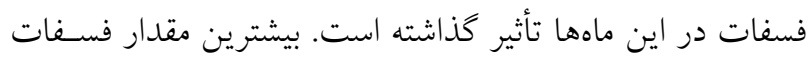

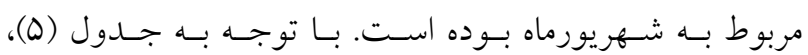

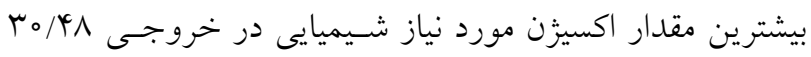

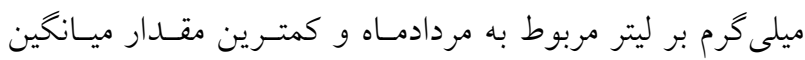

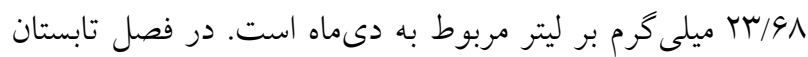

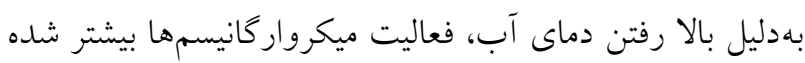

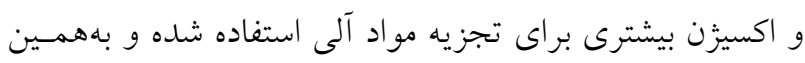

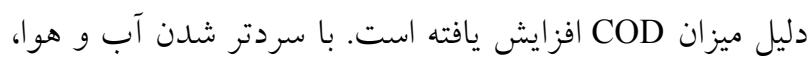

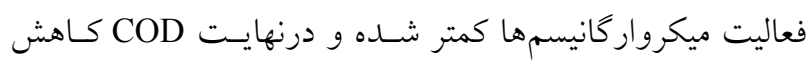

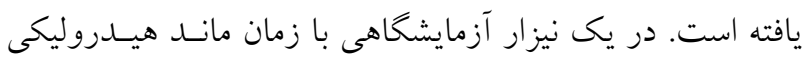

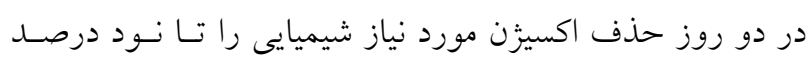

كزارش دادند (1) مز دوز جـدول (Y) و (V) مقايسـه ميـانخين فاكتورهـايى بــا اثـرات متقابل معنى دار در مكــان خروجسى و زمـانهـاى مختلـف دولف دوره

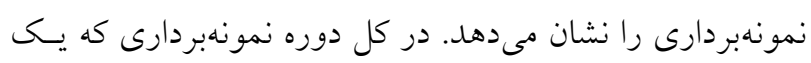

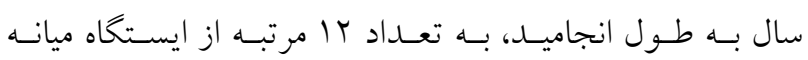
نمونهبردارى انجام شد. فاكتورهايى كه اثر متقابل آنها معنسى دار آنسار

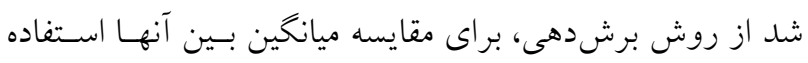

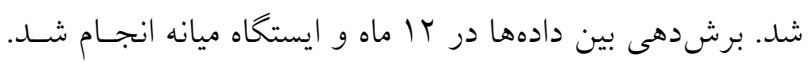

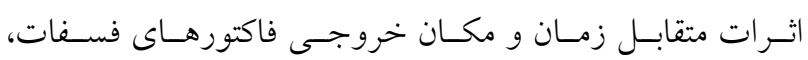

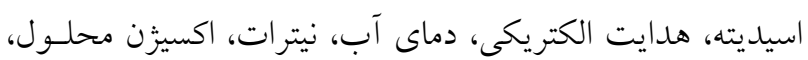

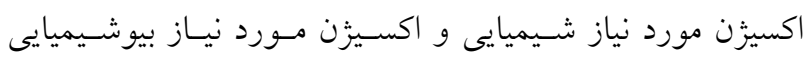

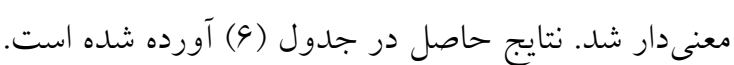

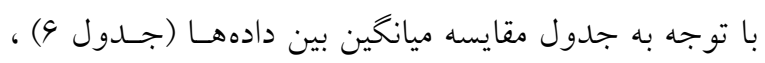

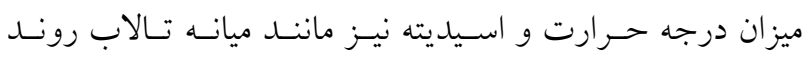
افزايشى داشته است. اسـيديته در محسدوده N/IV تـا هـ/9 قـرار داشت و قليايى بودن pH نشاندهنده درصد بالايى از نمكهــاى 
جدول 9. مقايسه ميانخين فاكتورهايى با اثرات متقابل معنىدار در مكان خروجى و زمانهاى مختلف دوره نمونهبردارى

\begin{tabular}{|c|c|c|c|c|c|}
\hline اكسيزنخواهي & هدايت الكتريكى & اكسيزن محلول & اسيديته & دما & ماههاى نمونهبردارى \\
\hline $\mid r / \Upsilon \wedge \pm \circ / \circ \Delta^{d}$ & $\Gamma / / Q_{ \pm \circ / \circ \Delta^{e}}$ & $1 / 9 V \pm \circ / \circ{ }^{4 b}$ & $\Lambda / \Lambda_{ \pm \circ} \mathrm{e}$ & $r q / \Delta r \pm \circ / Y I^{c}$ & خرداد \\
\hline 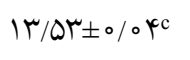 & $r / 19 \pm \circ / / 4 \mathrm{~d}$ & $1 / \mu \Delta \pm \circ / \circ \mu^{f}$ & $q / \uparrow \Delta \pm \circ /\left.0\right|^{a}$ & $r l / \circ r_{ \pm 0 / /} \mathrm{cb}$ & تير \\
\hline 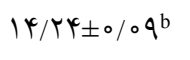 & $r / r_{ \pm} \circ / \circ q^{b}$ & $\circ / ৭ \wedge \pm \circ / \circ \Delta^{h}$ & $\Lambda / \mu| \pm 0 / 0|^{f}$ & 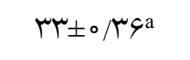 & مرداد \\
\hline $14 / 9 \pm \circ / \circ q^{a}$ & $r / \Delta_{ \pm} \circ / \circ \varphi^{4 a}$ & $\circ / V \Delta \pm \circ / \backslash \wedge^{i}$ & $N / Y Y_{ \pm} / \circ Y^{i}$ & $r \varepsilon / r_{ \pm 0} / / Y_{\mathrm{d}}$ & شهريور \\
\hline$|\circ / 4| \pm 0 / \circ \Leftrightarrow h$ & $r / Y Y_{ \pm 0} / 0 \mu^{c}$ & $1 / \circ V_{ \pm} \circ / \circ \varphi^{g}$ & $\Lambda /\left.\mu_{ \pm 0 / 0}\right|^{f}$ & $r \circ / \Delta V \pm \circ / / \Delta^{\mathrm{e}}$ & مهر \\
\hline$\| / \Lambda Y_{ \pm \circ / \circ \Lambda^{e}}$ & $\left.r_{ \pm 0 / 0}\right|^{h}$ & $1 / 1 \pm 0 / 09 \mathrm{~g}$ & $\Lambda / Y \pm 0 /\left.0\right|^{g}$ & $11 / T \Delta \pm \circ / /^{\mathrm{h}}$ & آبان \\
\hline$৭ / 9 \wedge \pm \circ / \circ \vee^{j}$ & 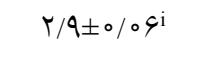 & $1 / 9 Y \pm \circ / \circ \Delta^{d}$ & $N / \Delta \mu_{ \pm} /\left.\circ\right|^{c}$ & $V / A Y \pm 0 / 01^{j}$ & 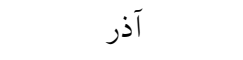 \\
\hline$\Lambda / V V \pm \circ / Y I^{1}$ & $\Gamma / \Lambda| \pm 0 /| q^{j}$ & $1 / \Lambda k_{ \pm 0 / 0} k^{c}$ & $\Lambda / Y^{\leftarrow} \Delta \pm \circ / 0 Y^{d}$ & $V / V Y \pm \circ / Y q k$ & دى \\
\hline$Q / \circ V \pm \circ / \circ \mu^{k}$ & $T / 9 \pm 0 / 0 \varphi^{i}$ & $T / Y \mid \pm 0 / 01^{a}$ & $N /\left.\Delta \mu_{ \pm 0 / 0}\right|^{c}$ & $9 / T \Delta \pm 0 / 19^{1}$ & بهمن \\
\hline$q / \wedge q \pm \circ / \uparrow V^{i}$ & $r / 01 \pm 0 / 0$ th & $1 / \wedge \Delta_{ \pm} \circ / \circ \varphi^{c}$ & $\Lambda / V I \pm \circ / \circ r^{b}$ & $1 \circ / V \Delta \pm \circ / 19^{i}$ & اسفند \\
\hline $11 / 1 \Delta_{ \pm} / \circ \mathrm{kg}^{\mathrm{cg}}$ & $r / \backslash \pm 0 / 0 \psi \mathrm{g}$ & $1 / 9 \wedge \pm 0 / 1 \mathrm{re}^{\mathrm{e}}$ & $N /\left|V_{ \pm} \circ / 0\right|^{h}$ & $\mid V / F \vee \pm 0 / 1 Q^{g}$ & فروردين \\
\hline $11 / 9 \mu_{ \pm}{ }^{f} f$ & $\Gamma / / \Gamma_{ \pm \circ / \circ \Delta^{f}}$ & $|/ \Gamma| \pm \circ / \circ V^{g}$ & $\Lambda / \Lambda_{ \pm} \pm / \circ \gamma^{\mathrm{e}}$ & $19 / 1 V \pm 0 / 10^{f}$ & ارديبهشت \\
\hline
\end{tabular}

جدول V- مقايسه ميانخين فاكتورهايى با اثرات متقابل معنىدار در مكان خروجى و زمانهاى مختلف دوره نمونهبردارى

\begin{tabular}{|c|c|c|c|c|}
\hline اكسيزن خواهى شيميايى & فسفات & آمونياك & 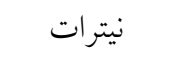 & ماههاى نمونهبردارى \\
\hline$T / 9 \Delta \pm \circ / \circ \Delta^{f}$ & $\circ / / Y_{ \pm 0 / 0 Y^{i}}$ & $\mid / \mathrm{VI} \pm \circ / 4 \varphi \mathrm{a}$ & $1 / \circ V \pm \circ / \circ 1^{f}$ & خرداد \\
\hline$\mu \Psi / \mu \Lambda \pm 0 / 0 \psi \mathrm{Ye}$ & $\circ / V_{ \pm} \circ / \circ \varphi g$ & $r / \mu \mid \pm \circ / \circ \wedge^{f}$ & $1 / Y Y_{ \pm 0} d$ & تير \\
\hline$r Q / q r \pm 0 / \circ q^{b}$ & $\circ / \Delta Y \pm 0 / 0 /^{\mathrm{e}}$ & $\Gamma / 19 \pm \circ / \circ \Delta^{d}$ & $1 / \mu \mu_{ \pm} / 0 \mu^{c}$ & مرداد \\
\hline$r V / r V \pm \circ / \circ q^{a}$ & $\circ / V \Delta \pm \circ / \circ \varphi^{a}$ & $r / 9 V \pm 0 /\left.0\right|^{a}$ & $r / \Delta \varphi \pm \circ / \circ \Delta^{a}$ & 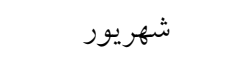 \\
\hline$r \Delta / r V \pm 0 / 0 \varphi^{d}$ & $\circ / 9 \mu_{ \pm 0} c$ & $\Gamma / \Lambda \pm 0 /\left.0\right|^{\mathrm{e}}$ & $1 / 1 r_{ \pm \circ / \circ r^{e}}$ & 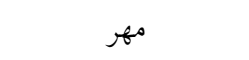 \\
\hline$r \Delta / \Delta \pm \circ / \circ \wedge^{c}$ & $\circ / V I \pm \circ / \circ q^{b}$ & $r / Y Y \pm 0 / 1 l^{c}$ & $1 / 49 \pm 0 / 0 r^{b}$ & 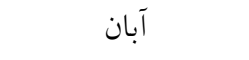 \\
\hline$Y Y / G Y_{ \pm 0} / 0 V g$ & $\circ / \Delta \wedge \pm \circ / \circ)^{d}$ & $r / I \pm 0 / 0 \varphi^{c h}$ & $\left|/ T_{ \pm} / 0\right|^{c}$ & آذر \\
\hline$|9 / 4 \wedge \pm 0 / \digamma|^{k}$ & $\circ / \mu 1 \pm \circ g$ & $r / \Lambda 1 \pm \circ / / 1^{b}$ & $\circ / 99 \pm 0 / 01^{g}$ & دى \\
\hline$r / / 90 \pm 0 / 0 r^{\mathrm{j}}$ & $0 / 49 \pm 0 /\left.0\right|^{f}$ & $|/ 4 \varphi \pm 0 / 0|^{k}$ & $\circ / N \Psi_{ \pm} /\left.\circ\right|^{i}$ & بهمن \\
\hline$r / / ৭ 0 \pm \circ / 4 V^{i}$ & $\circ / \mu_{ \pm} / \circ 1^{\mathrm{h}}$ & $1 / 09 \pm 0 / 01^{j}$ & $\circ /\left.9 \varphi_{ \pm 0 / 0}\right|^{j}$ & اسفند \\
\hline$Y Y / T \Delta \pm 0 / 0$ \%h & $0 / 4 q \pm 0 /\left.0\right|^{f}$ & $1 / \Lambda \mu_{ \pm 0 / 0} \varphi^{i}$ & $\circ / 91 \pm 0 / 01^{\mathrm{h}}$ & فروردين \\
\hline$Y r / V \pm \circ g$ & $0 / q \mu_{ \pm} /\left.0\right|^{c}$ & $r / Y r_{ \pm} \circ / \circ Y^{g}$ & $\mid / Y Y_{ \pm 0 / 0} \varphi^{d}$ & ارديبهشت \\
\hline
\end{tabular}


آمونياك، ميزان آمونياك افزايش يافته است.

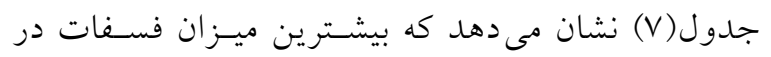

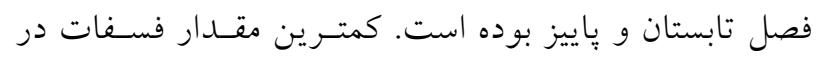

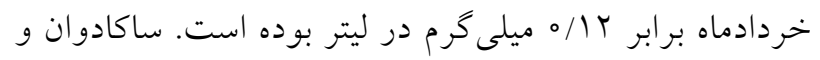
باور براى حذف فسفات و نيترات فاضلاب تصفيه شــده از سيستمهاى تصفيه تالابى استفاده كردند به اين نتيجه رسيدند

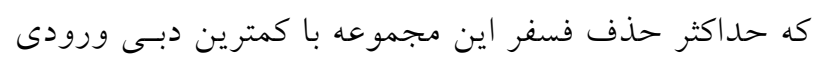

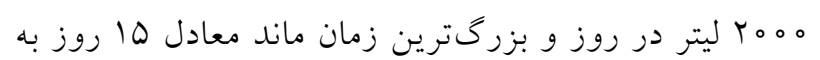

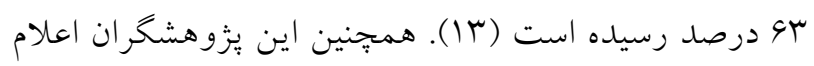
داشتند كه هر جند غلظـت فسـفر پِّـاب خروجسى در همـهـ

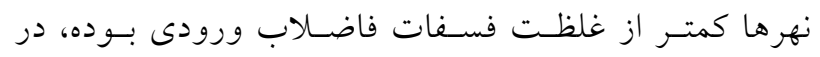

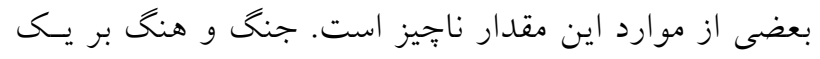

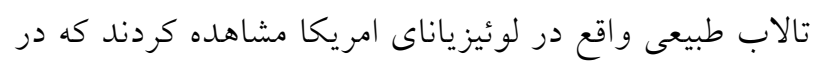

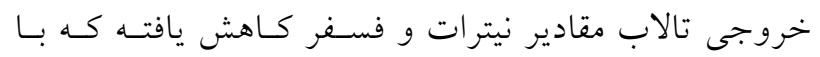

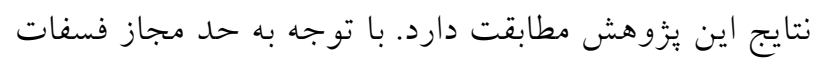

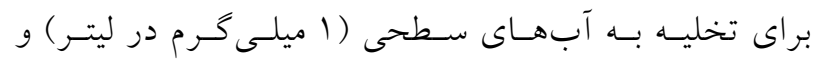

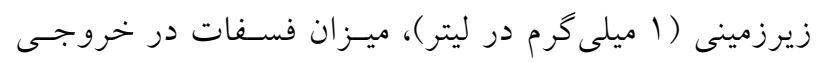

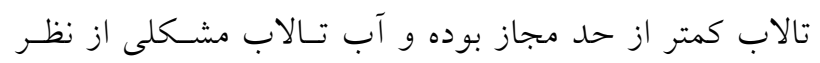

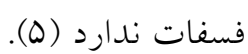
بيشترين مقدار اكسيزن مورد نياز شسيميايى خروجسى TY/OV

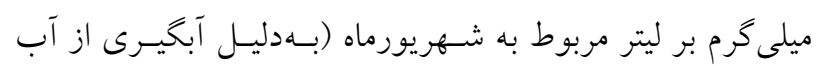

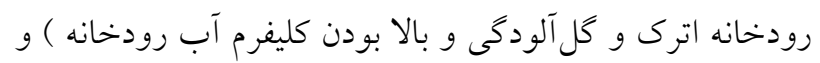

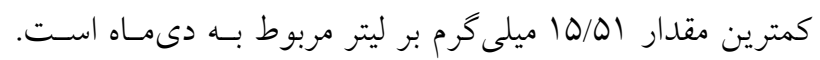

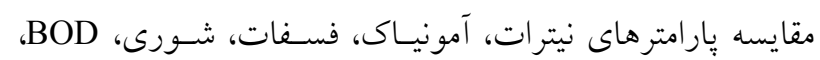

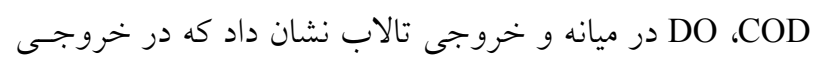

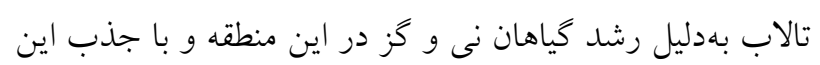

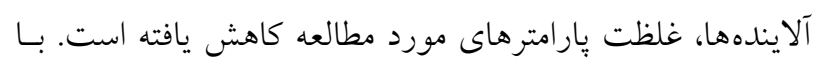

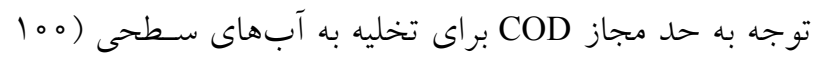

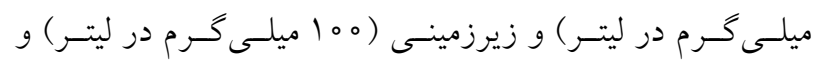

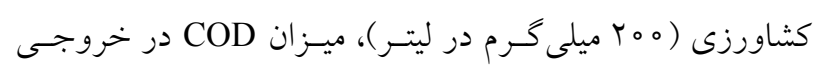

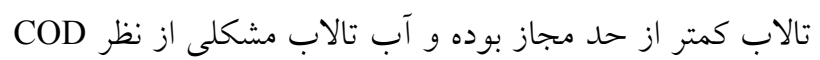
ندارد.
عملكرد رويشى جمعيتهاى مختلف گز شاهى در اراضى شور

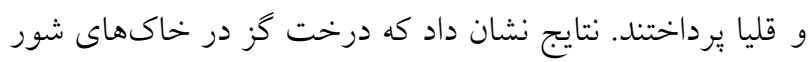
به خوبى رشد مى كند (11) (11).

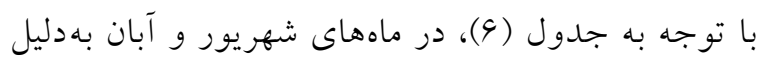

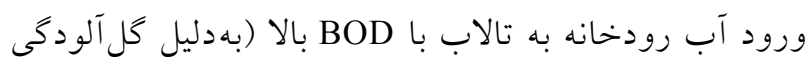

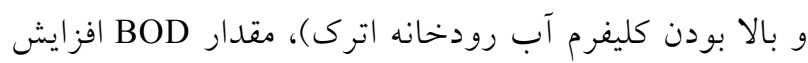

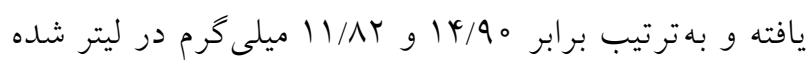

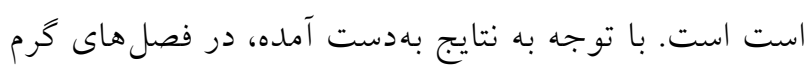

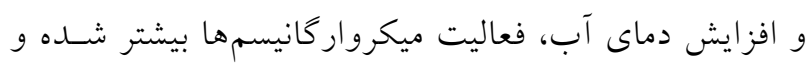

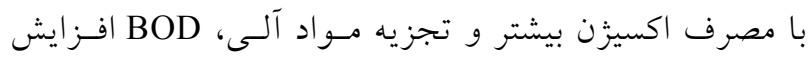
يافته است. با توجه به حد مجاز BOD براى تخليسه بـه آب-

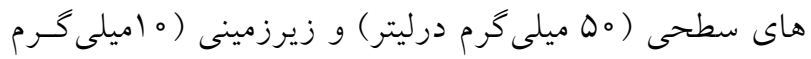

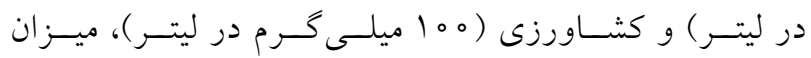
BOD مشكلى از نظر BOD ندارد. نتايج اين يزوهش با نتايج قلى ابلى

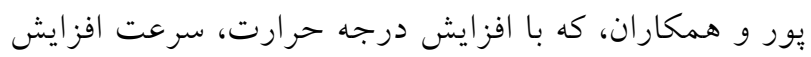

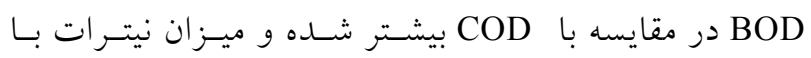
افزايش دما افزايش و كيفيت آب كاهش يافته است، مطابقت

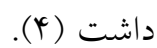
با توجه به جدول (V)، بيشترين مقدار نيترات در شهريور

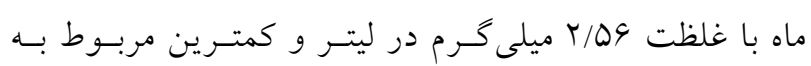

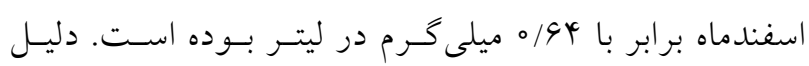

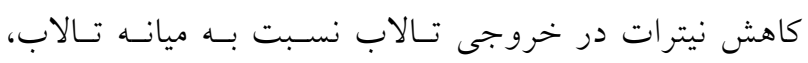

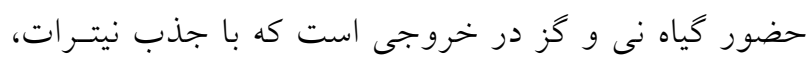

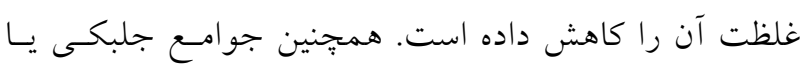

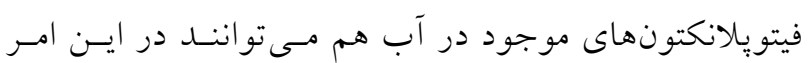

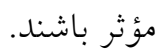

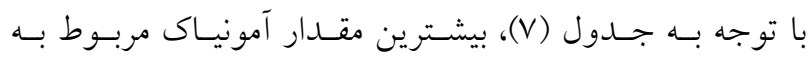

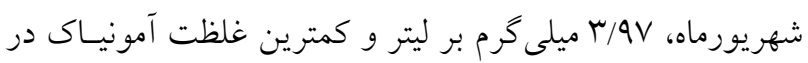

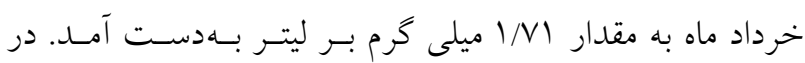

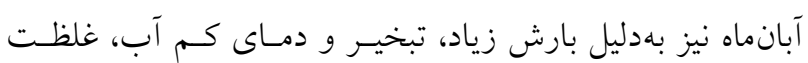

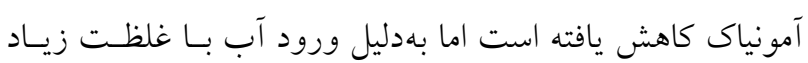




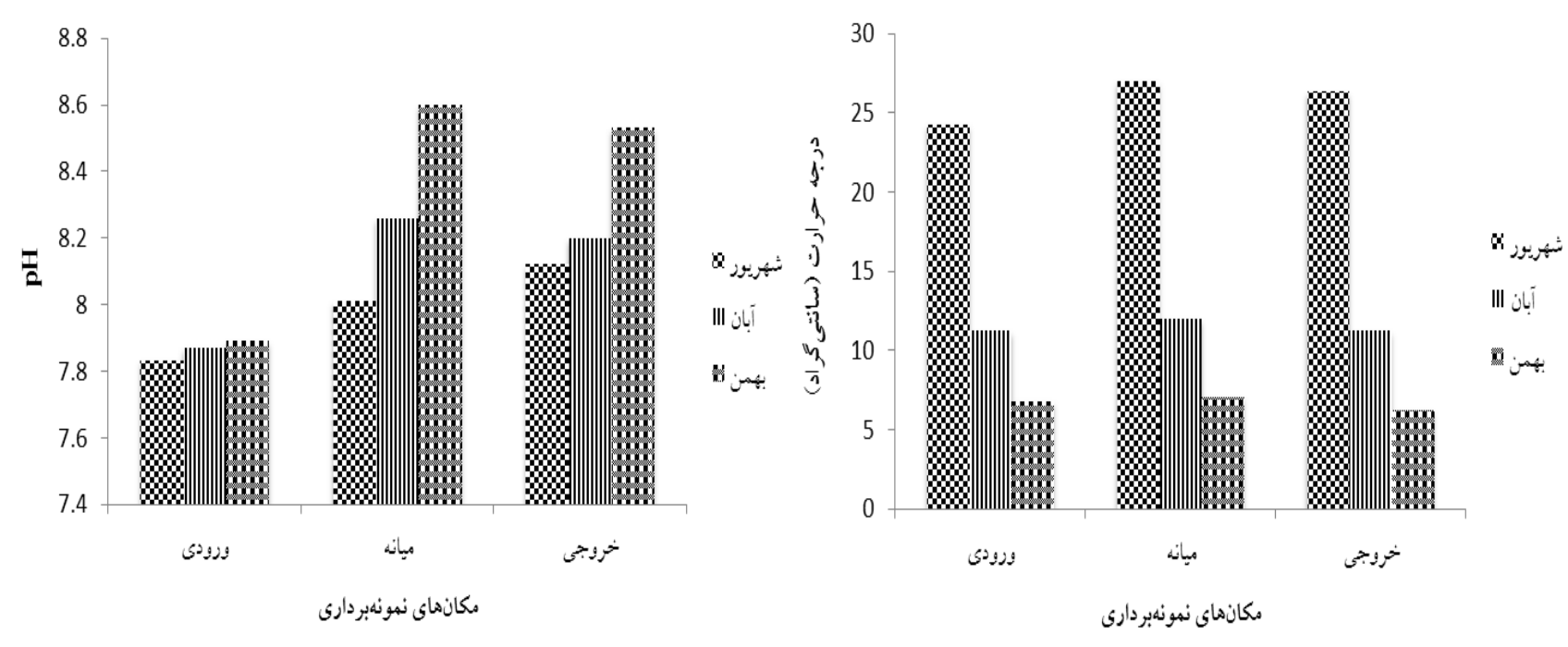

شكل r. تغييرات: الف) pH و ب) درجه حرارت در مكانهاى مختلف تالاب در ماههاى آبكيرى

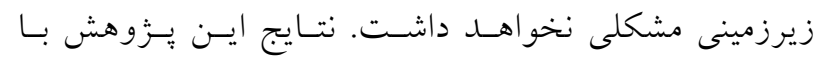

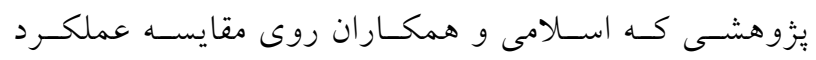

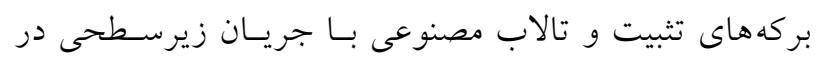

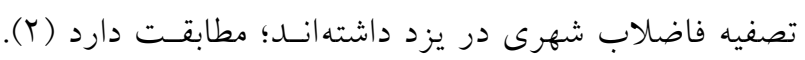

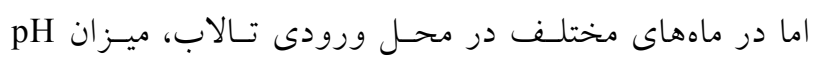

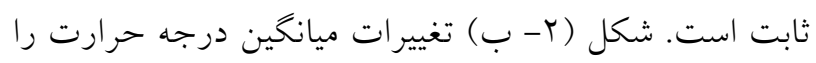

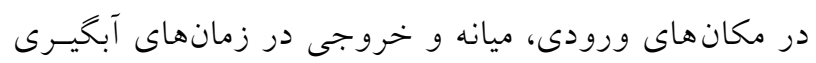

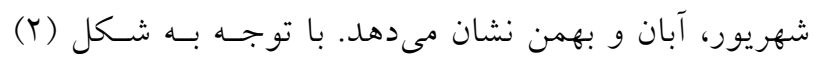

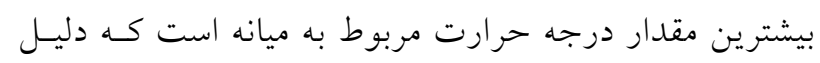

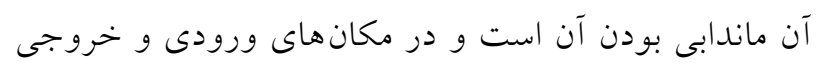

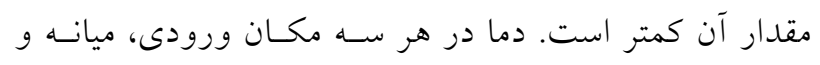
خروجى تفاوت معنسى دارى داشـت. بيشـترين دمـا در ميانسه

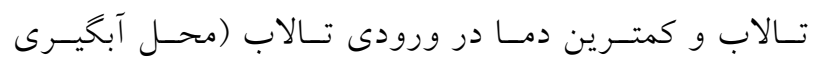

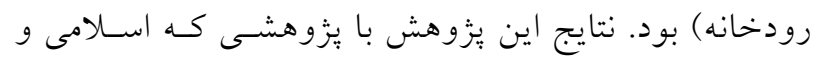

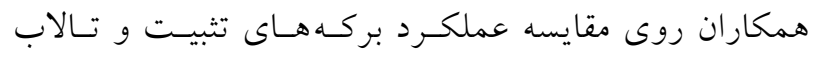

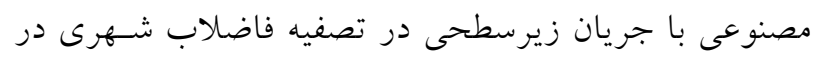

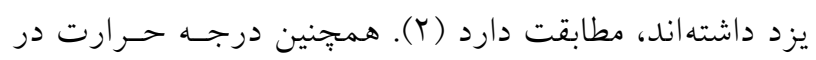
هر مكان در ماههاى مختلف معنادار بود. اثر دما روى اكسيزّن

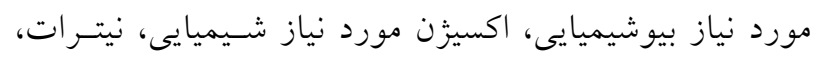

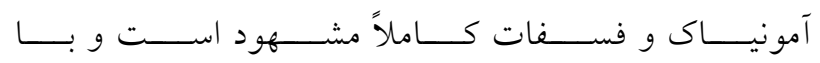

رحمانى و همكاران در تحقيقى بـه بررسى عملكـــ نيزارهـاى

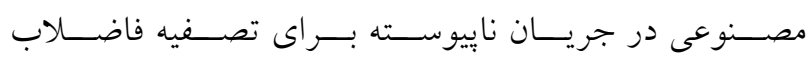

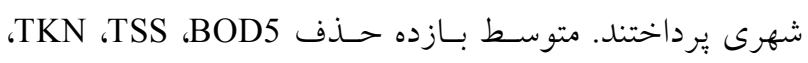
TC ور جريان بيوسته براى تركيب بيشتصـفيه و نيـزار

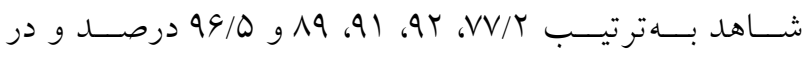

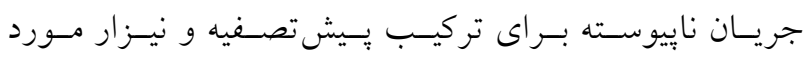

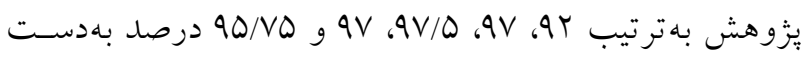

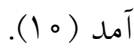

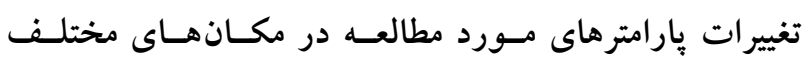

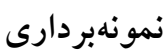
شكل (Y) تغييرات pH و درجه حرارت را در مكانهاى مختلف تالاب در ماههاى آبخيرى نشان مى دهد.

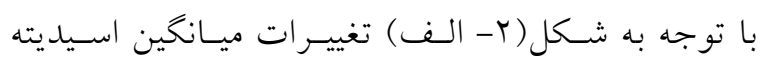

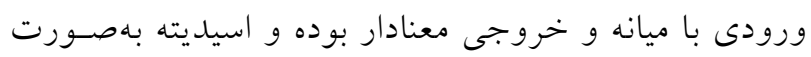

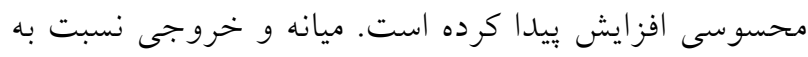

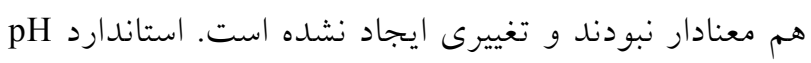

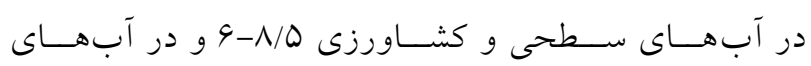

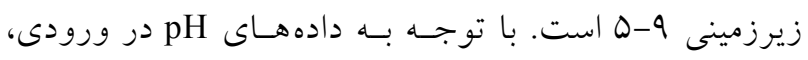

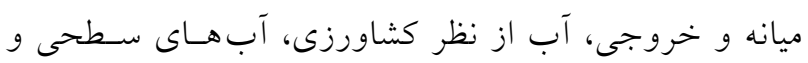




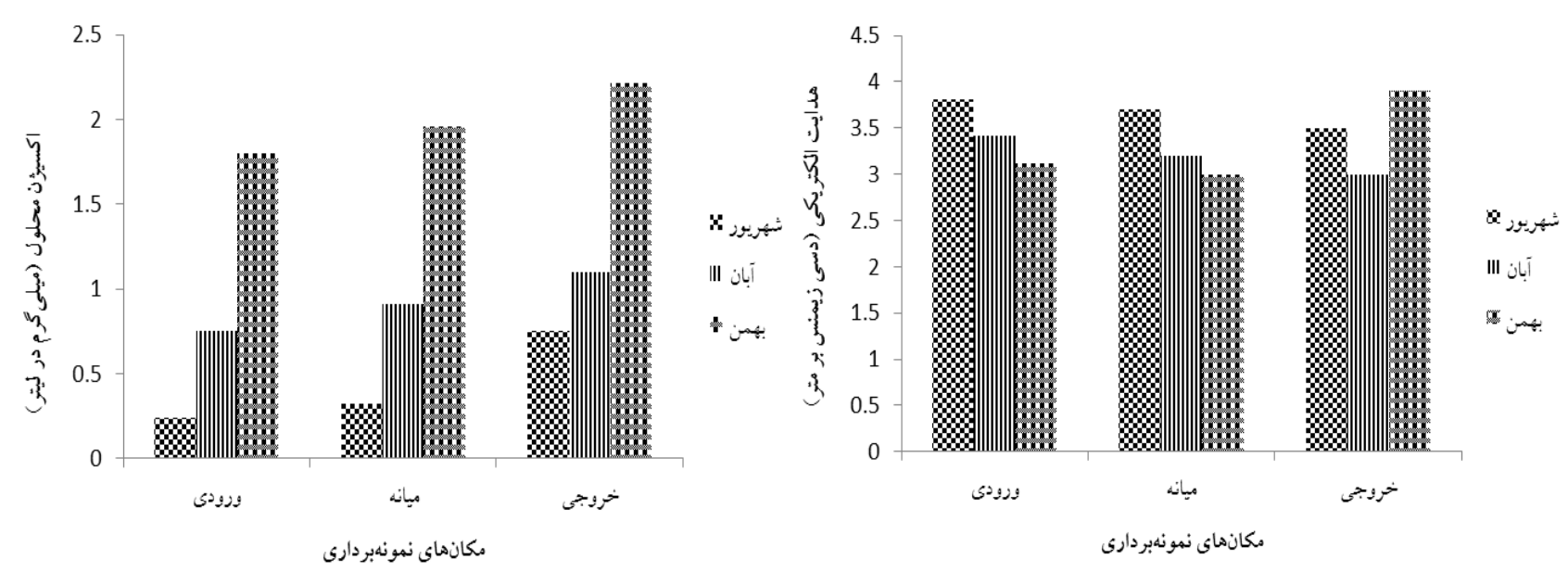

شكل r. الف) تغييرات اكسيزن محلول و ب) هدايت الكتريكى در مكانهاى مختلف تالاب در ماههاى آبخيرى

نتايج بهدست آمده، تالاب در خروجسى، ما 1 درصـد شـورى

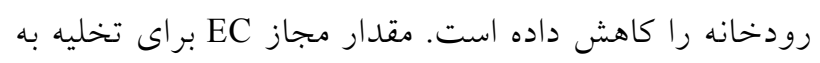

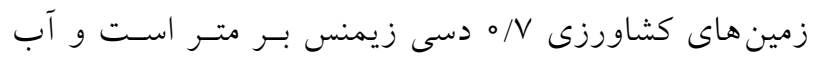

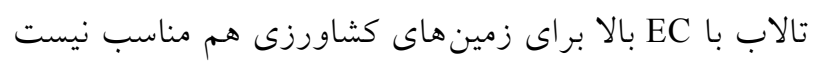

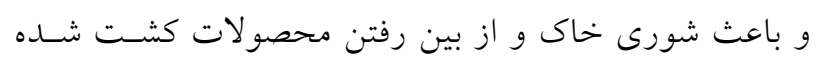

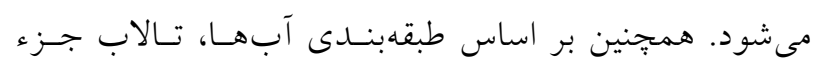

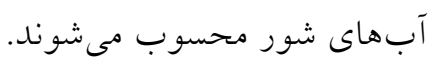

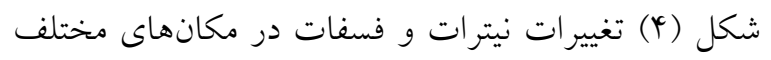

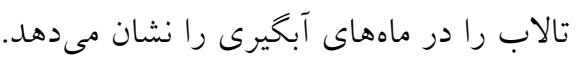

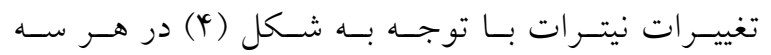

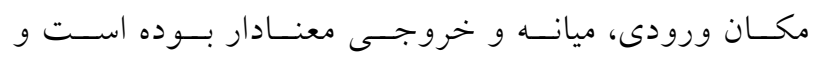
روند كاهشى از ورودى بهسمت خروجى داشته است. ميـزان

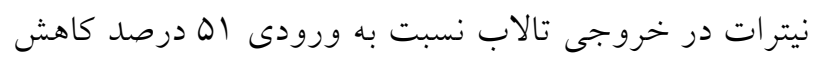

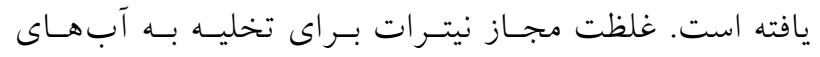

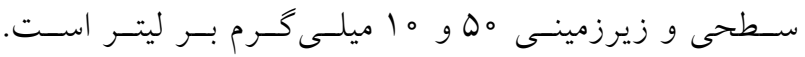

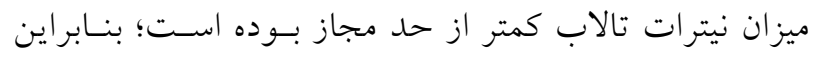

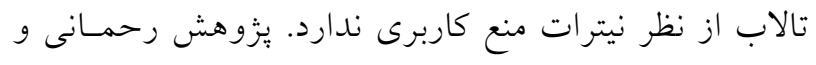

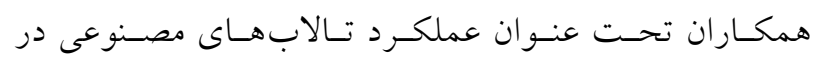

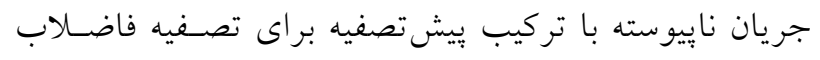

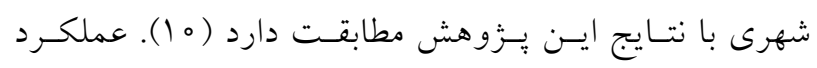

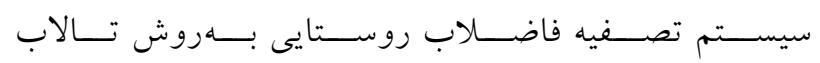

افزايش و كاهش دما راندمان حذف اين بارامترها نيز تغيير مى

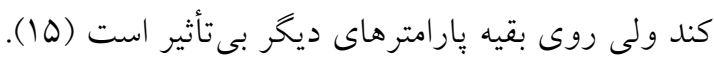

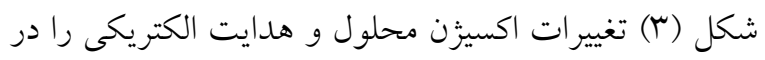
مكانهاى مختلف تالاب در ماههاى آبخيرى نشان مىدهد.

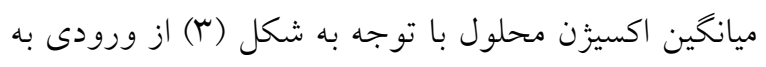

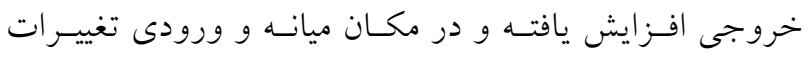

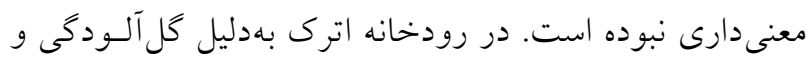

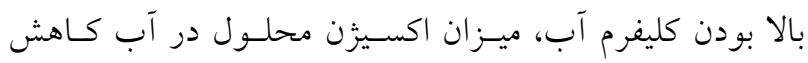

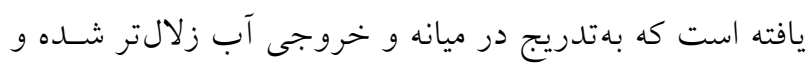

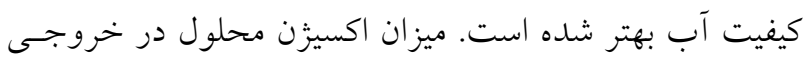

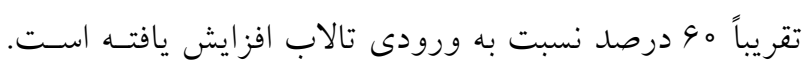

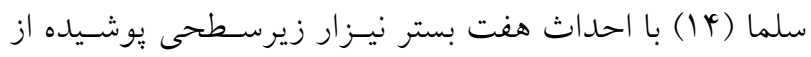

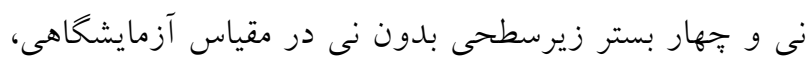

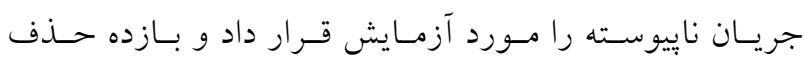
اكسيزن محلول را در هر دو بستر نزديك بههم كزارش كرد.

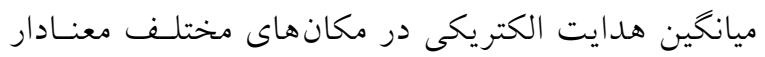
بوده و از ورودى به خروجى هدايت الكتريكى كمتر شده كه

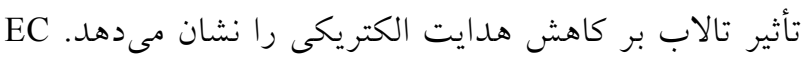

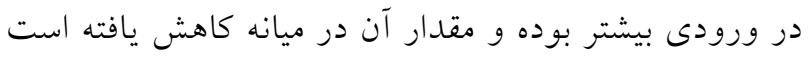
و بهسمت خروجى كاهش بيشتر بوده است. كاهش EC ميانه

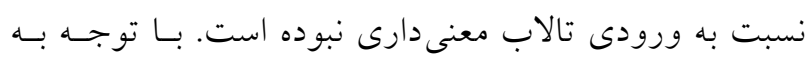



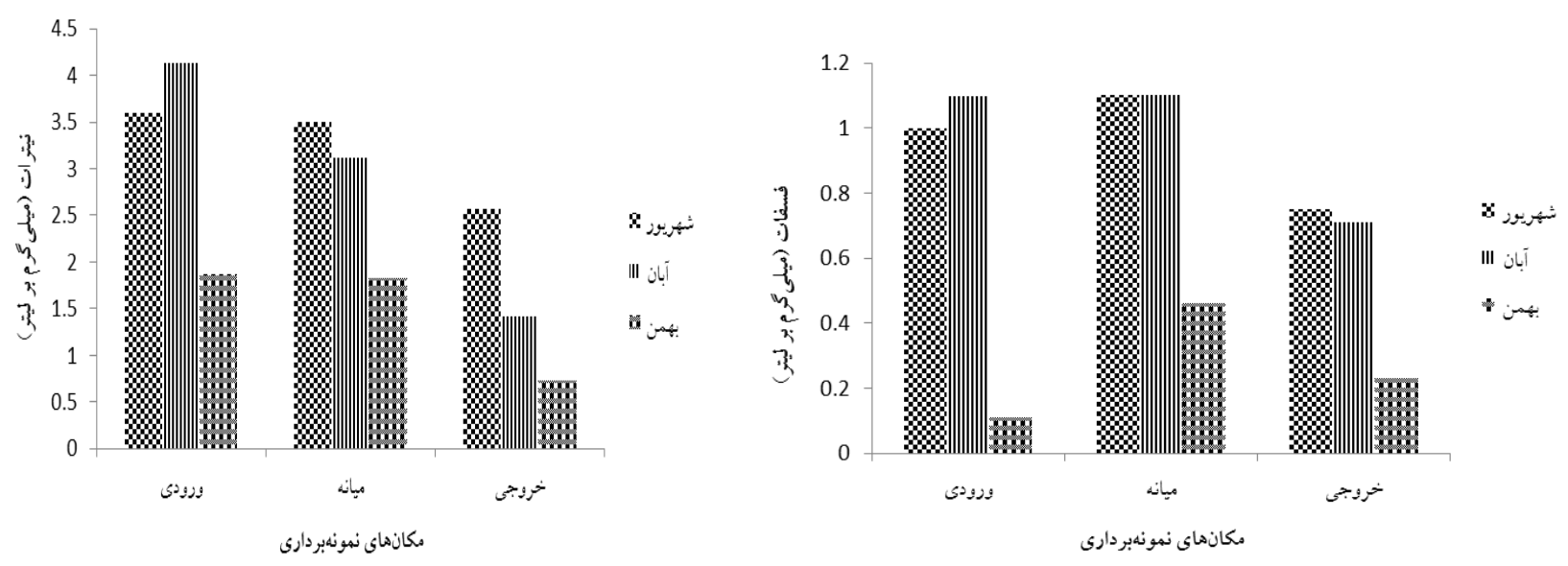

شكل f. الف) تغييرات نيترات و ب) فسفات در مكانهاى مختلف تالاب در ماههاى آبخيرى
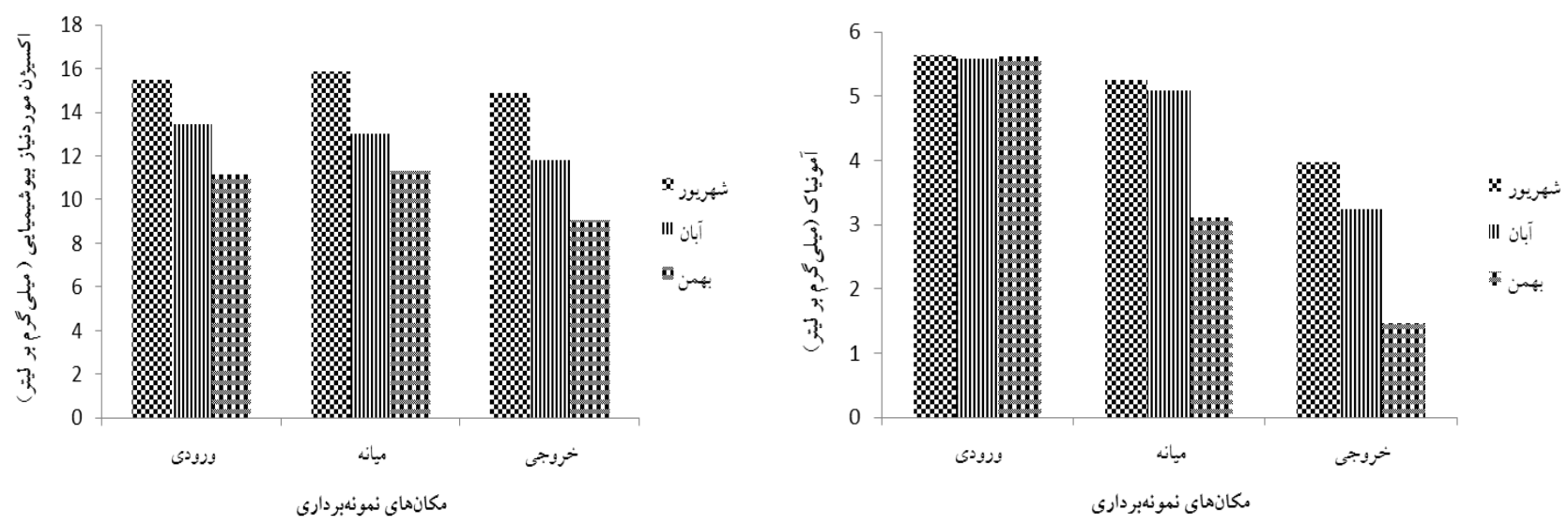

شكل ه. الف) تغييراتBOD و ب) آمونياك در مكانهاى مختلف تالاب در ماههاى آبخيرى

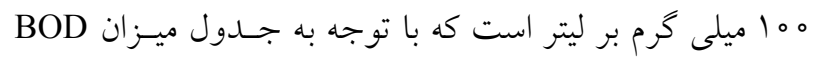

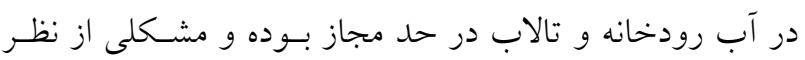
كاربرد نخواهد داشت. يُزوهش رحمانى و همكاران تحت عنو عنوان

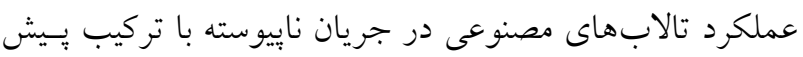

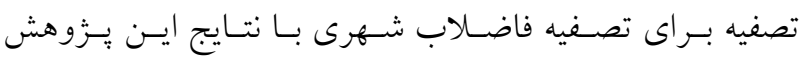

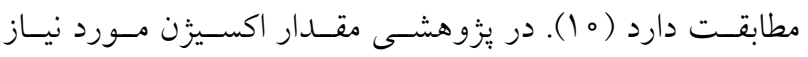
بيوشيميايى در خروجى كاهش داشته كه با اين يزوهش مطابقت

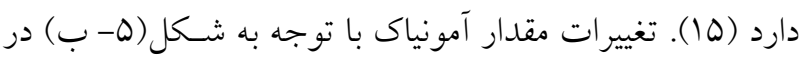

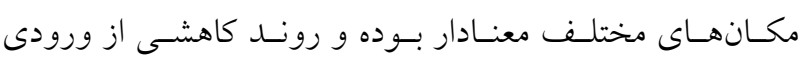

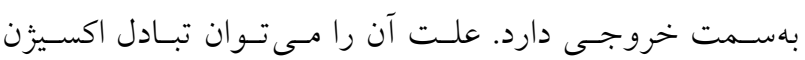
اتمسفرى در تالاب با جريان زيرسطحى و همجنين بالا بودن
مصنوعى مقدار نيترات در خروجى كـاهش داشـته كـهـ بـا ايسن

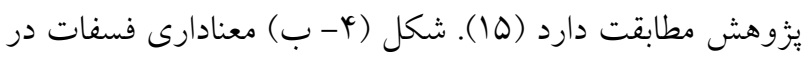

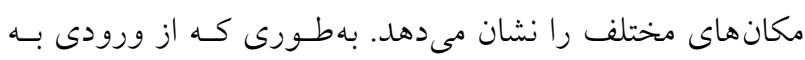
سمت خروجى روند كاهشى داشته است. حد مجاز تخليه فسفر

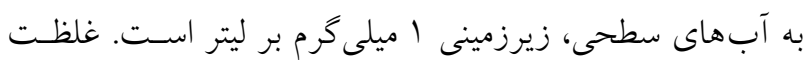

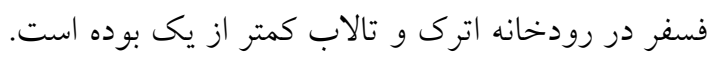

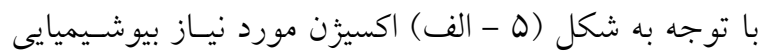
در مكانهاى ورودي، ميانه و خروجى اختلاف معنادارى نداشته

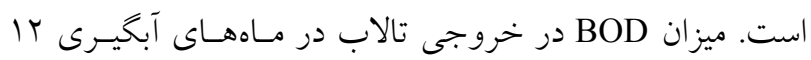

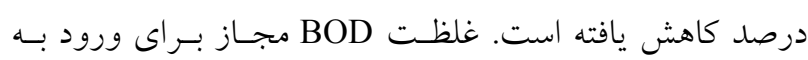

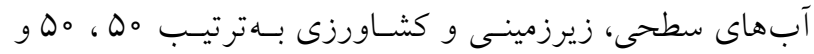




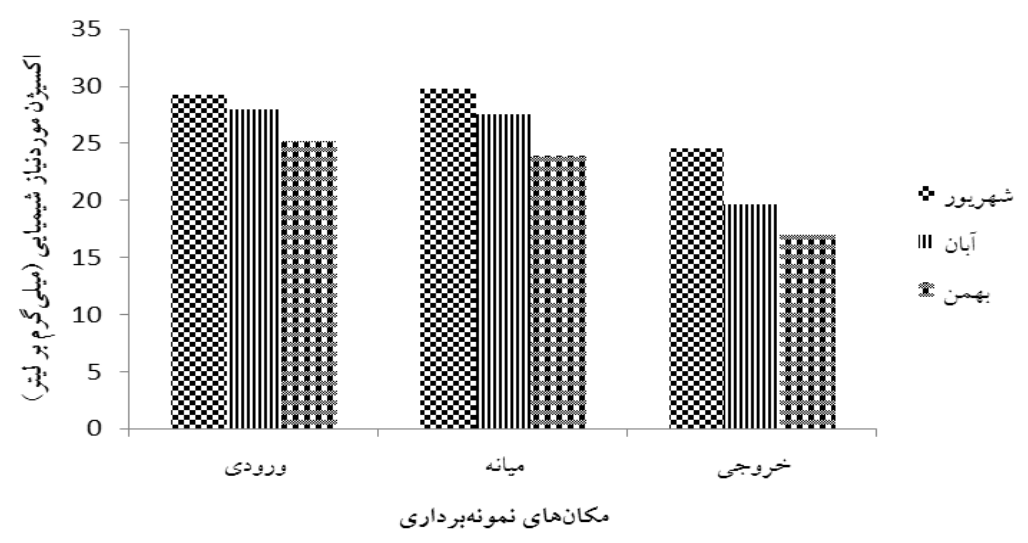

شكل 9. تغييرات COD در مكانهاى مختلف تالاب در ماههاى آبخيرى

ورودى بيشتر بوده و كاهش آن بهسمت خروجى بيشستر بـوده

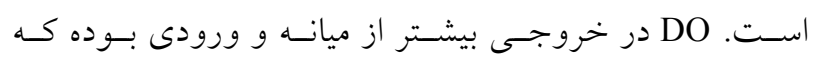

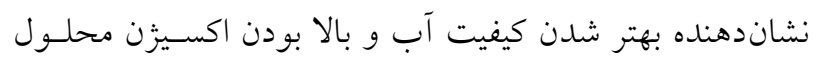
در خروجى تالاب بوده اسـت.

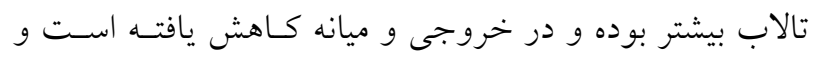

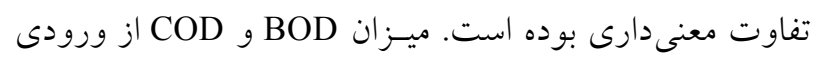

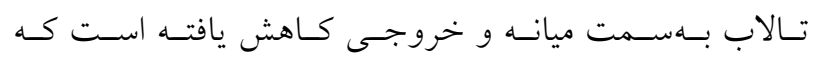
نشاندهنده كم شدن مصرف اكسيزن محلول براى تجزيه ميه مـواد

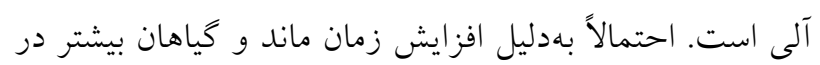

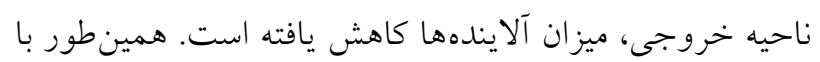

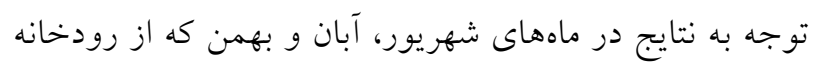

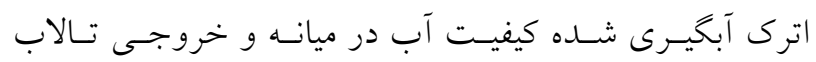

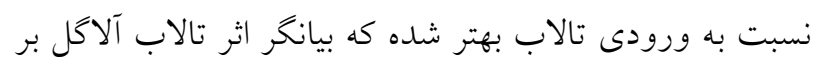

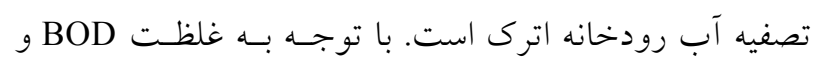

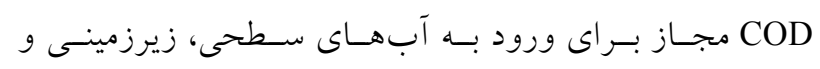

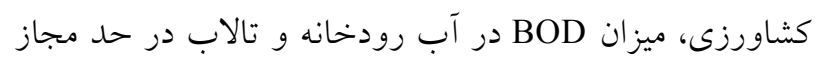

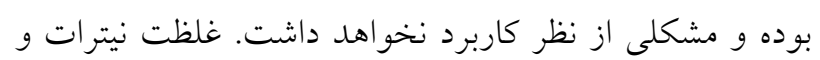

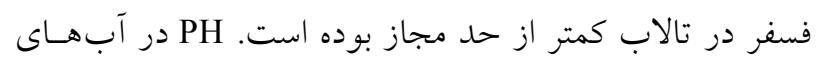
سطحى و زيرزمينى در محدودهه مجاز قرار كرفته است. بارامتر

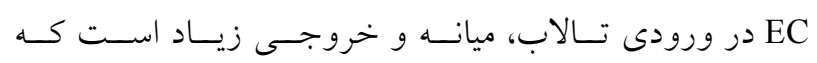

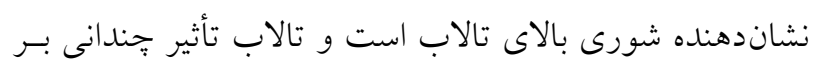

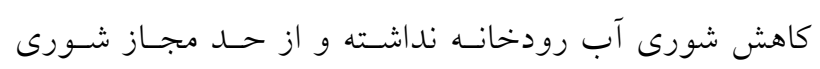

حذف آمونيوم بـهـ علـت تـأمين اكسـيزن لازم توسط فتوسـتنز جلبكى و هوادهى اتمسفرى دانست.

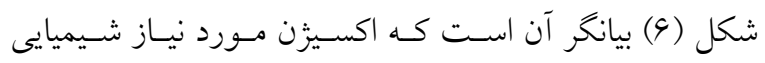

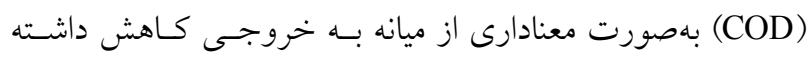

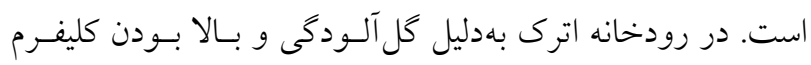

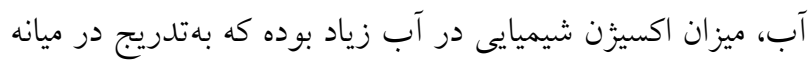

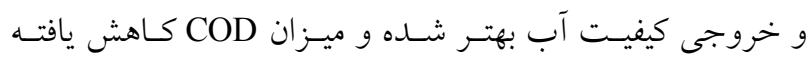

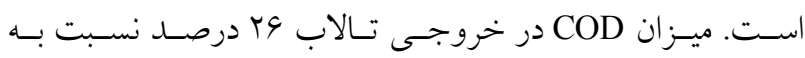

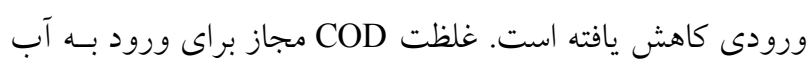

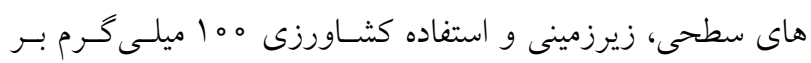

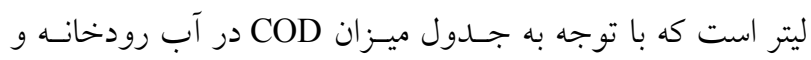
تالاب در حد مجاز بوده و مشكلى از نظر كاربرد نخواهد داشت.

\section{نتيجه گيرى}

نتايج حاصل از بررسى كيفيت آب تالاب آلاكل در سـه مكـان

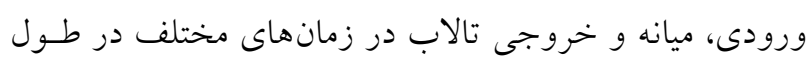

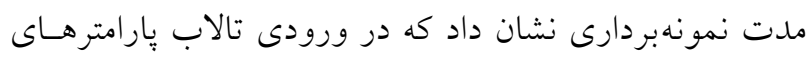

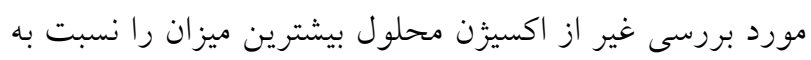

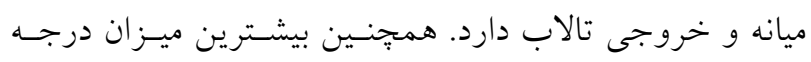

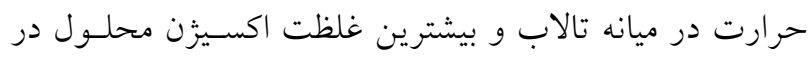

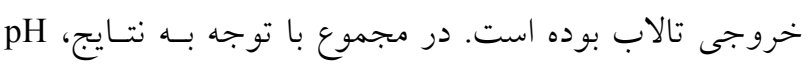

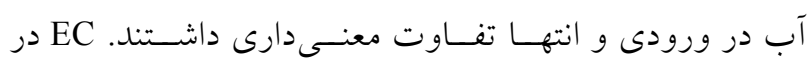




$$
\text { آب هاى سطحى خيلى بيشتر است. با توجه به نتايج بـهدسـت }
$$

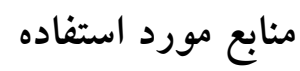

1. Abbaspoor, M. 1993. Envionmental Engineering. Tehran: Azad University Scientific Publishing Center. (In Farsi).

2. Eslami, H., S., Ghalmani, A. Salehi, D. Hoseini Shahi, S. Ghaleh Askari and P. Talebi .2014. Comparison of the performance of stabilized ponds and artificial wetlands with submersible flow in urban wastewater treatment in Yazd. Water and Wastewater Journal 6: 100-106. (In Farsi).

3. Hajibeigloo, M. and W. B. Sheikh. 2017. Location and establishment of riverbed in watersheds (Case study: Tajan River, Razavi Khorasan Province, Iran). Journal of Water and Soil Protection 24(4): 1-22. (In Farsi).

4. Gholipour, A. and A. Alamatian. 2015. The effect of temperature variations and channel roughness on the quality of waste water in Mashhad province using numerical modeling. Water and Sustainable Development Journal 2(1): 5158. (In Farsi).

5. Jeng, H. and Y. J. Hong. 2005. Assessment of a natural wetland for use in wastewater remediation. Enviromental Monitoring and Assessment 111: 113-131.

6. Mburu, N., R. D. Sanchez, D. P. Rousseau, J. J. A. Van Bruggen, G. Thumbi, O. R. Stein and P. B. Hook. 2012. Simulation of carbon, nitrogen and sulphur conversion in batch-operated experimental wetland mesocosms. Ecological Engineering Journal 42: 304-315.

7. Meftah Holgh, M. 2011. Water quality zoning with different quality indices (Case study: Atrak river). Journal of Water and Soil Protection 2: 211-220. (In Farsi).

8. Mirzaee, A. and N. Jafarzadeh. 2011. Investigating the efficiency of underground artificial wetlands in reduction of Ammonia $\mathrm{N}$ and Phosphorus artificial wastewater similar to home-made laboratory scale. Health Research Journal. (In Farsi).

9. Nafar, R., A. Zamani, A. Parizangeneh and F. Khandoozi. 2018. Investigation of the concentration of some heavy metals in the water of Almaghel, Alagol and Ajigol wetlands in Golestan province. Fourth International Conference on Environmental Planning and Management. (2 July 2018). (In Farsi).

10. Rahmaani Sanee, A., N. Mehrdadi, A. Azimi and A. Torabian.2008. Investigation effect of artificial forearms in batch flow for wastewater treatment. Water and Wastewater Journal 20(2): 32-40. (In Farsi).

11. Sadeghzadeh, M., D. Azadfar and R. Mirakhoree. 2014. Study of vegetative function of different populations in saline and alkaline land. Wood and Forest Journal 22(2): 151-165. (In Farsi).

12. Salari, H., A. H. Hasani, M. Barghee, A. R. Yazdan Baksh and H. Rezaee. 2011. Function of Rural Wastewater System by Artificial Wetland Method in Nitrogen and Phosphorus Wastewater Removal (Case study: Muradtepe Village). Water and Wastewater Journal 23(40): 40-47.(In Farsi)

13. Sakadevan, K. and H .J. Bavor. 1995. Phosphate adsorption characteristics of soils, slags and zeolite to be used as substrate in constructed wetland systems. Water Research Journal 32(2): 393-399.

14. Selma, C. A. 2001. Treatment of wastewater by natural systems. Environmental International 26(3): 189-195.

15. Tanveer, S., P. Biprojit, A. Rumana, A. M. Abdullah and S. Guangzhi. 2016. Floating constructed wetland for the treatment of polluted river water a pilot scale study on seasonal variation and shock load. Chemical Engineering Journal 287: 62-37.

16. Yeganeh Bakhteiari, A., A. Ghaheri, S. Farzadpour, A. Hekmat and M. Moradhaseli. 2006. Investigating the performance of wetlands in the treatment of urban Wastewater in cold regions of the Garrison. Development and Research of Wastewater Water.

17. Yousefi, M. and B. Mohseni. 2010. Nitrogen and phosphorus removal from wastewater by subsurface wetlands planted with Iris pseudacorus, Ecological Engineering 70: 32-39.

18. Yousefi Z., A. Mesdaghinia and M. Ghyasedin. 2001. The role of Water hyacinth in bacterial removal at the subsurface artificial wetland. Journal of Mazandaran University Medicene Science 11(31): 7-15. (In Farsi). 


\title{
The Effect of Alagol Wetland on the Water Treatment of Atrak River
}

\author{
R. Rakhshani, M. Farasati ${ }^{*}$ A. Heshmatpour and M. Seyedian
}

(Received: March 13-2019; Accepted: July 27-2019)

\begin{abstract}
In this research, the impact of the Alagol wetland on the water treatment of Atrak River was studied. From June, 2016, to May, 2017, on the fifteenth day of the month, four samples of water were collected from the middle and the outlet of the wetland. Also, the wetland was fed only in the months of September, November and February. The parameters of acidity, electrical conductivity, phosphate, nitrate, dissolved oxygen, biochemical oxygen demand, chemical oxygen and ammonia were measured. The water $\mathrm{pH}$ at the entrance and exit was significantly different. EC was higher at the entrance, and its value was decreased in the middle and output. DO in the outlet of the wetland was higher than that in the middle and inlet, indicating the improved water quality and high dissolved oxygen in the wetland output. $\mathrm{NO}_{3}, \mathrm{NH}_{4}$, $\mathrm{PO}_{4}, \mathrm{BOD}$ and COD were higher at the entrance to the wetland; also, it was decreased in the outlet and middle, and the difference was significant. Further, according to the results of September, November and February, which were fed to the wetland, water quality in the middle and outlet of the wetland was improved toward the entrance of the wetland. According to the results, Alagol wetlands could reduce the phosphorus, ammonia, BOD, COD and DO, and their concentrations were lower than the limit. However, given that the salinity at the entrance of wetland was too high, its amount in the output was higher than the standard limit and the wetland could not significantly reduce salinity. The results of this study showed that that of water pollution in the inlet, except that the dissolved oxygen parameters and the temperature were high and decreased in the middle outlet. Due to the quality of the wetland outlet, Alagol wetland water could be used for fish farming centers.
\end{abstract}

Keywords: Water quality, Natural treatment, Alagol wetland, Nitrate

1- Pasture and Watershed Department, College of Agricultur, Gonbad University, Gonbad Kavoos, Iran.

*: Corresponding author, Email: farasati2760@gmail.com 